\title{
Modified Fuzzy Logic Method for Materials Selection in Mechanical Engineering Design
}

\section{Mostafa Sharifan}

Sharif University of Technology

Ali Abedian ( $\sim$ abedian@sharif.edu )

Sharif University of Technology https://orcid.org/0000-0003-4724-7433

\section{Pardis Razaghian}

Sharif University of Technology

\section{Research Article}

Keywords: Fuzzy logic, Multi-criteria decision making, Materials selection, Materials Indices

Posted Date: October 21st, 2021

DOl: https://doi.org/10.21203/rs.3.rs-892307/v1

License: (c) (i) This work is licensed under a Creative Commons Attribution 4.0 International License. Read Full License 


\section{Title:}

\section{Modified fuzzy logic method for materials selection in mechanical engineering design}

\section{Authors:}

Mostafa Sharifan (First Author)

Affiliation: Department of Aerospace Engineering, Sharif University of Technology, Tehran, Iran

Email: mostafa.sharifan@ae.sharif.edu

Ali Abedian (Corresponding Author)

Affiliation: Department of Aerospace Engineering, Sharif University of Technology, Tehran, Iran

Email: abedian@sharif.edu

Pardis Razaghian

Affiliation: Department of Aerospace Engineering, Sharif University of Technology, Tehran, Iran

Email: pardis.razaghian@ae.sharif.edu 


\section{Abstract:}

Materials selection is one of the primary steps in designing products, including mechanical ones. As a result, researchers are continuously developing simple, accurate, and feasible techniques to enhance the performance of the designed component by selecting the optimum materials from a wide variety of candidate materials. In this research work, a modified fuzzy approach referred to as Modified Fuzzy Logic Method (MFLM) is proposed to provide some highly appreciated advantages besides resolving some of the substantial shortcomings of the existing solutions. Customizing the method based on the designer's knowledge and level of expertise, simultaneous consideration of qualitative and quantitative properties, and high accuracy in the ranking of candidate materials are some of the significant benefits of MFLM in comparison to the available alternative methods. While, complexity, high volume computational efforts, and more are amongst the resolved drawbacks. Moreover, the produced results show the power and simplicity of the technique in solving complex problems like materials selection for a gas turbine blade which involves a high range working temperature.

Keywords:

Fuzzy logic, Multi-criteria decision making, Materials selection, Materials Indices 


\section{Introduction}

Multi-Criteria Decision-Making (MCDM) problems are frequent in human beings' daily life. Engineers also deal with these problems and consistently seek to find the optimum choices in different stages of the design cycle. In the meantime, materials selection is one of the most challenging steps, owing to the fact that a wide range of materials available coupled with various and sometimes hard-to-process criteria make it even more demanding. During the past decades, researchers have proposed several strategies for materials selection to face the difficulties. Ashby [1-ㅗ] by utilizing materials selection charts as well as multi-objective optimization method, and Farag [ㄷ] and Manshdi [] by introducing weighted property method (WPM) and modified digital logic (MDL), respectively, are amongst the pioneers who tried to simplify the procedure of materials selection.

Furthermore, Shanian [ ] ] has proposed the TOPSIS method, a simple and recognized technique by active researchers in this field. Analytical hierarchy process [ㅇ] (AHP) is also another admired approach. Among newfound methods, Electre [9] by pairwise comparison of candidate materials, Z-transformation [10] by using statistical operators, and Jahan's technique [11] by applying ordinal data strived to enhance the procedure of materials selection. Moreover, many of the criteria weighting techniques [12-14] have provided subjective and objective weighting coefficients for different attributes.

In more recent attempts, due to advancements in computing techniques, several researchers have investigated the use of relevant Machine Learning (ML) methods to assist the manufacturing process by adopting the most suitable materials for the assumed applications according to their properties and in-service operation. Under this focus, both supervised and unsupervised learning models can perform classifications and regressions on materials data [15-19]. These computing systems are robust in learning complex non-linear functions and 
extracting information from large datasets; nevertheless, they require preliminary training and can be computationally demanding. Also, hyperparameters tuning is an inevitable and challenging part of applying any ML algorithm.

To be noted, as another related direction, some researchers have developed various strategies for multi-material (hybrid) design of components to select the proper materials for their intended functions [20-24]. These systems endeavor to select the discrete variables (i.e., material types) and optimize the continuous parameters like components' geometry to simultaneously achieve multiple objectives, such as satisfying structural performance, low cost, and lightweight. Solving such multi-objective optimization (MOO) problems is challenging due to the presence of various variables and goals, as well as highly nonlinear constraints [25]. Therefore, some recent works have employed metaheuristic (nature-inspired) optimization

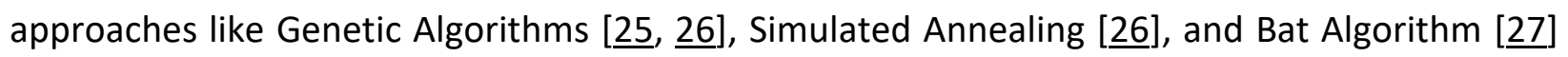
to find the ideal solutions based on the presumed constraints and defined objective functions. These algorithms are proven to be powerful in minimizing the cost functions and detecting global optima [28, 29]; however, when more than one objective is targeted, metaheuristic approaches should be supported with a multi-criteria decision analysis approach. MCDM methods provide a systematic trade-off between the assumed targets, and help one form proper objective functions. As an instance, Zhang [25] applied the well-known TOPSIS decisionmaking technique []] to optimize concrete mixture proportions based on metaheuristic and $\mathrm{ML}$ algorithms.

The above-said MCDM methodologies work well when reliable, accurate, and adequate numerical data is at hand, an assumption that is not well-fitted with the vague and uncertain nature of materials selection problems. Data acquisition can become a time-consuming, expensive, and sometimes infeasible task. Accordingly, many material attributes are described either with ranges of numbers rather than precise amounts or with linguistic terms. With this in mind, also add the fact that variations in the working environments of components can cause the properties of their constituent materials to change. In this sense, having a concrete way of modeling uncertainties can ease the decision-making process and enhance the reliability of 
outputs. The fuzzy logic concept [으, which provides us with the formal principles of approximate reasoning, has been widely used for materials selection in the past two decades. Rao [31] employed Graph theory in the fuzzy space. Sarfaraz [32] utilized fuzzy membership functions and tried to select the optimum materials based on defined IF-THEN rules. Moreover, Babu [33] proposed a similar work using the Grey relational analysis concept in the fuzzy environment. However, the high complexity of these methods in defining IF-THEN rules prevents their extensive application. Some researchers have also tried to implement conventional numerical methods in the fuzzy scope. Rathod [34] and Mayyas [35] separately modified the TOPSIS technique to apply it in the fuzzy environment, taking into account the fuzzy membership functions for materials properties and the weighting coefficients of the criteria, as well as using a few simple operators. Reddy [36] also ranked the materials by presenting a TOPSIS-based framework in the fuzzy space while considering a combination of subjective and objective weighting values for the criteria. Gul [37] implemented the Promethee method in the fuzzy space by defining a set of operators for trapezoidal membership functions. Applying the mentioned approaches is not recommended while only dealing with measurable attributes because the fuzzy functions cannot correctly differentiate the properties of the materials. Consequently, the accuracy of the ranking system deteriorates.

Efforts have not been limited to employing conventional approaches in the fuzzy environment; some researchers strived to introduce the principles of axiomatic design (i.e., independence and information axioms) to the field of multi-attribute decision-making based on vague and uncertain data. Kulak [요 developed a Fuzzy multi-attribute selection approach by combining the concept of axiomatic design with the analytic hierarchy process []ㅡ. Cieck [39] modified the fuzzy axiomatic design-model selection interface (FAD-MSI) [40] to make it compliance with the nature of the materials selection scheme. Khandekar [41] also offered an axiomatic designbased approach considering triangular fuzzy membership functions for the design ratings, materials properties, and weighting coefficients of attributes. However, in many cases, the fuzzy membership functions of the design ratings stand far from the functions of materials properties, and the proper evaluation cannot be obtained. 
In the following, an easily programed fuzzy logic-based method for materials selection is proposed to remove the aforesaid drawbacks and reduce the computational efforts. Also, the capabilities of the method are examined using common problems in mechanical engineering design.

\section{Method description}

MFLM falls under the weighted property category of materials selection methodologies [ $[5]$. It means that it is a form of criteria weighting technique combined with a ranking system that usually converts crisp data into normalized values. In the following, the step-by-step procedure of the MFLM is explained.

\subsection{Step 1: Parametric study of the problem to specify the constraints and performance requirements of the component}

In materials selection schemes, choosing either materials properties or materials indices is the first move of the process. In mechanical cases where extraction of materials indices is applicable, authors prefer to employ them, as long as the correlations between indices are considered in the criteria weighting process (see reference [14]). However, in many other applications, such as resin selection for a mechanical composite part, it is not pragmatic to practice materials indices. Therefore, materials properties can be considered for these types of applications. Of Note, in the proposed method, there are no limits in choosing either of the said criteria; thus, the decision-maker can use any of them based on conditions of the problem and availability of the required information. Materials properties or indices are assumed either

beneficial or cost, meaning that their higher or lower values are more favorable for the application, respectively. 


\subsection{Step 2: Formation of the matrix of attributes}

In this step, a matrix consisting of the properties or indices of the candidate materials should be formed as shown below;

$$
\begin{gathered}
C_{1} \\
D= \\
Y_{1} \\
\cdots \\
Y_{i} \\
\cdots \\
Y_{n}
\end{gathered}\left[\begin{array}{ccccc}
x_{11} & \cdots & C_{j j} & \cdots & C_{m} \\
\cdots & \cdots & \cdots & \cdots & \cdots \\
x_{i 1} & \cdots & x_{i j} & \cdots & x_{i m} \\
\cdots & \cdots & \cdots & \cdots & \cdots \\
x_{n 1} & \cdots & x_{n j} & \cdots & x_{n m}
\end{array}\right]_{n \times m}
$$

where $Y_{i}$ is the $i^{\text {th }}$ candidate material, $C_{j}$ represents the $j^{\text {th }}$ attribute, and $x_{i j}$ is the numerical value of $j^{\text {th }}$ attribute corresponding to $i^{\text {th }}$ material. Also, $n$ and $m$ are the total numbers of considered materials and attributes, respectively. Even though a large number of candidate materials does not affect the originality and performance of the method, the decision-maker is advised to primarily eliminate the unsatisfying candidates using materials screening procedures like Ashby's method [1-] to decrease the volume of calculations.

\subsection{Step 3: Definition of a set of fuzzy membership functions for each criterion}

In this step, specifying a set of membership functions is first explained for quantitatively stated criteria and then for qualitatively expressed ones. For the former, two options for mapping interval of functions are in service; either a design span, which is defined subjectively or the range of materials properties (i.e., distance from max to $\mathrm{min}$ ). One can avoid the influences of materials properties outside of the desired span by mapping proper fuzzy functions in the design interval. In this sense, no matter how extreme the properties are, if they exceed the limit values (design range borders), their normalized quantities will be the same. This data treatment enables the system to neglect the superiority of out-of-the-box materials over one another. On the other hand, in the absence of enough design knowledge, the method still maintains its 
efficiency, and sets of functions can be in the distance from maximum to minimum of materials properties. A linguistic term is also assigned to each membership function that shows the assumed qualitative perspective.

For qualitatively stated criteria, fuzzy membership functions are defined based on the assigned linguistic terms of candidate materials. Each linguistic term demands a membership function, and all groups of functions are mapped between zero and one. A comprehensive explanation about fuzzy logic and implementation of fuzzy set theory in materials selection is presented in reference [32]. As an example, the triangular membership functions considered for the cost criterion are shown in Fig. 1.

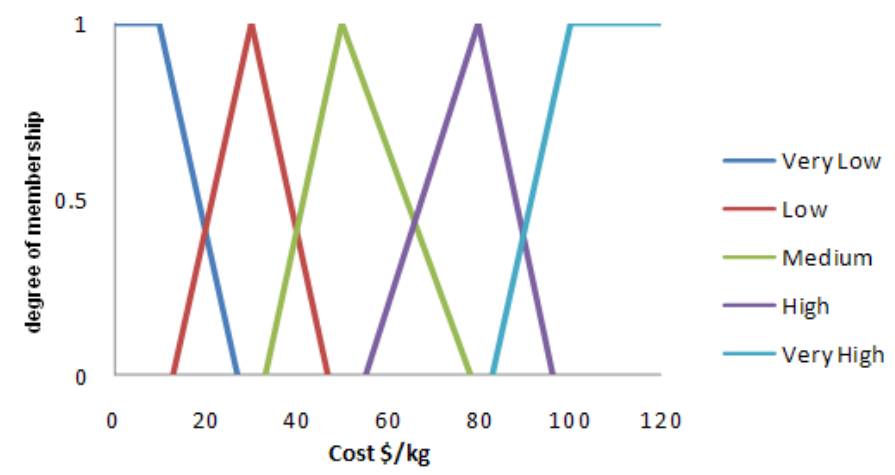

Fig. 1 Fuzzy membership functions for cost criterion

\subsection{Step 4: Determination of an equivalent value for each fuzzy membership function}

In this step, the considered linguistic terms of the functions are converted into equivalent values. Functions with more desirable positions in the assumed range receive higher values than the rest. Calculation of equivalent values is inspired by Rao's works [프, $\underline{31}, \underline{42}]$. Unfortunately, the articles published by Rao do not mention how exactly these values are obtained. However, by a close analysis of the geometry of membership functions and employing the trial and error approach, the formulas were extracted. The equivalent value is a dimensionless quantity between zero and one, which is defined by Eq. (1) according to Fig. 2; 


$$
\left\{\begin{array}{lc}
U_{f_{i}}=\frac{1+\left(Z_{M i}-Z_{G i}\right)}{2} & \text { for beneficial criteria } \\
U_{f_{i}}=\frac{1-\left(Z_{M i}-Z_{G i}\right)}{2} & \text { for cost criteria }
\end{array}\right.
$$

where $U_{f_{i}}$ is the equivalent value and $Z_{M i}$ and $Z_{G i}$ depend on the geometrical status of the membership function. $Z_{M i}$ and $Z_{G i}$ are the measuring tools for the right and left branches of a triangular function and help the designer to identify the location of a membership function in the defined scope and assign a numerical value to each one. To elaborate on Eq. (1), consider shifting the membership function in Fig. 2 to the right side of the design span. As it goes further, $Z_{M i}$ increases and $Z_{G i}$ decreases, meaning that the equivalent value for a function corresponding to a beneficial criterion rises. In other words, for a beneficial criterion, as a membership function approaches the maximum value of the design range $\left(x_{\max }\right)$, its equivalent value increases. Eventually, if the decision-maker considers an "exactly equal to" type function, in which $a_{i}, b_{i}$, and $c_{i}$ happen to be equal to the value of $x_{\max }$, the equivalent value for that function would be one which is the maximum number that a function can receive. Note that vice versa of the above applies to cost criterion functions.

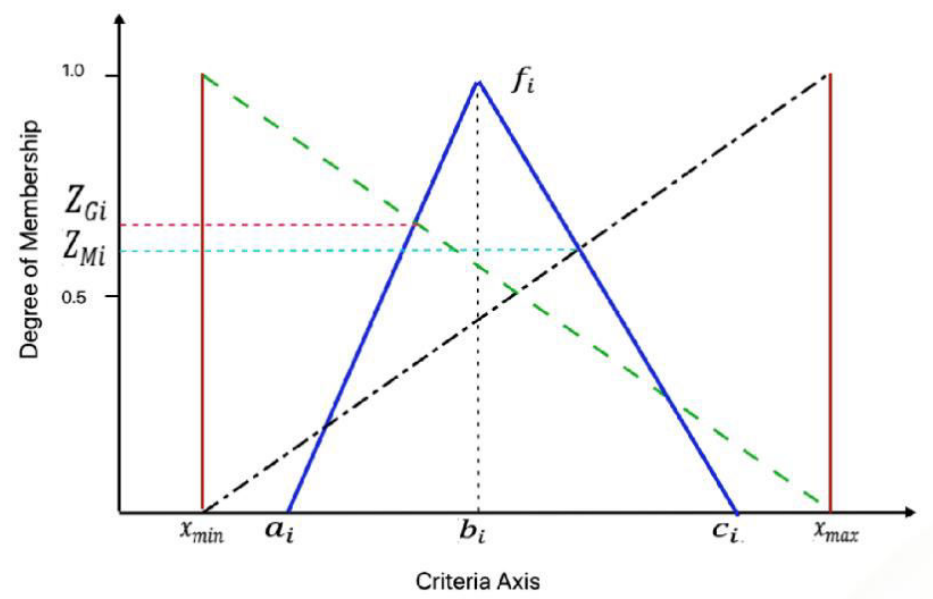

Fig. 2 Calculation of equivalent values for membership functions

This value should be calculated for all membership functions. For triangular functions, the values of $Z_{M i}$ and $Z_{G i}$ are calculated using Eq. (2); 


$$
\begin{aligned}
& Z_{M i}=\frac{\left(c_{i}-x_{\min }\right)}{\left(\left(x_{\max }-x_{\min }\right)-\left(b_{i}-c_{i}\right)\right)} \\
& Z_{G i}=\frac{\left(x_{\text {max }}-a_{i}\right)}{\left(\left(x_{\max }-x_{\text {min }}\right)+\left(b_{i}-a_{i}\right)\right)}
\end{aligned}
$$

$x_{\min }$ and $x_{\max }$ determine the presumed scope; while, $a_{i}, b_{i}$, and $c_{i}$ fully identify the position of the function, and all of them are geometrically shown in Fig. 2. Eq. (2) is obtained by calculating the intersection values of the function and its crossing lines.

\subsection{Step 5: Normalizing the attributes matrix [D] using fuzzy membership functions and their equivalent values}

Given the matrix of attributes [D] and sets of membership functions as input data, the normalized values of candidate materials for different criteria can be calculated. For example, assuming $x_{i j}$ is the cost of $i^{\text {th }}$ material. The normalized value of $x_{i j}$ is calculated based on Eq. (3) and Fig. 3:

$$
r_{i j}=\frac{1}{2}\left[\frac{\left(f_{i+1}\left(x_{i j}\right)-f_{i}\left(x_{i j}\right)\right) \times\left(U_{f_{i+1}}-U_{f_{i}}\right)}{\left(1-\min \left(f_{i+1}\left(x_{i j}\right), f_{i}\left(x_{i j}\right)\right)\right)}+\left(U_{f_{i+1}}+U_{f_{i}}\right)\right], \quad b_{i} \leq x_{i j} \leq b_{i+1}
$$

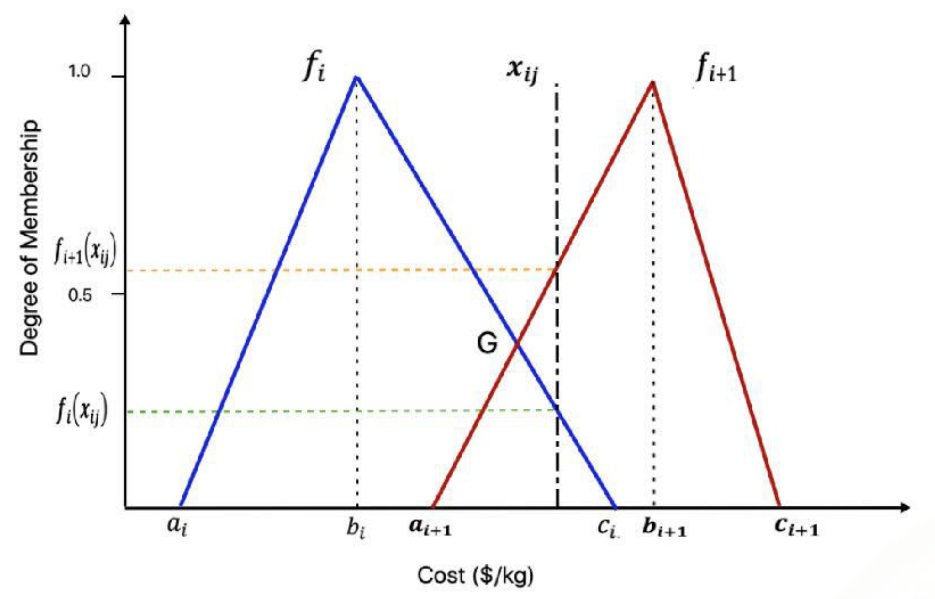

Fig. 3 Normalizing the crisp data of candidate materials 
In order to understand the logic behind the suggested normalization approach, consider that $x_{i j}$ happens to be $b_{i}$ or $b_{i+1}$. According to Eq. (3), $r_{i j}$ for these points are found to be equal to $U_{f_{i}}$ and $U_{f_{i+1}}$, respectively. It means that for the crisp values which belong entirely to a membership function (degree of membership is one), that function's equivalent value is considered as the normalized number. However, if $x_{i j}$ happens right at the intersection of two surrounding membership functions (point $\mathrm{G}$ in Fig. 3 ) and equally belongs to both functions, $r_{i j}$ would be $\left(U_{f_{i+1}}+U_{f_{i}}\right) / 2$. Based on the above explanation, Eq. (3) converts material properties or indices into the normalized values using a linear combination of the equivalent values of the surrounding membership functions. Also, notice that candidate materials with properties out of the design scope of each criterion receive the equivalent values of the closest membership functions as their normalized amounts.

The procedure is much more straightforward for qualitatively stated criteria, and the equivalent values of defined membership functions are considered as their normalized numbers. For example, consider that "High", "Medium", and "Low" are three linguistic terms describing the shock resistance property of candidate materials. First, one should map a set of three membership functions for shock resistance criterion based on step 3 and then calculate the corresponding equivalent values according to step 4. Candidate materials that demonstrate high shock resistance receive the equivalent value of "High" membership function as their normalized amounts. The same applies to the remaining functions. Finally, the input matrix [D] is converted into the normalized matrix $[R]$ as shown in the following;

$$
R=\left[\begin{array}{ccccc}
r_{11} & \ldots & r_{1 j} & \ldots & r_{1 m} \\
\ldots & \ldots & \ldots & \ldots & \ldots \\
r_{i 1} & \ldots & r_{i j} & \ldots & r_{i m} \\
\ldots & \ldots & \ldots & \ldots & \ldots \\
r_{n 1} & \ldots & r_{n j} & \ldots & r_{n m}
\end{array}\right]_{n \times m}
$$




\subsection{Step 6: Calculation of the weighting vector}

In this step, a coefficient between zero and one is assigned to each criterion which shows the importance of attributes in satisfying the desired purposes of the application. These values can be obtained utilizing objective, subjective, or integrated weighting methods [12-14]. In the present research work, MDL [ $[\underline{6}$ is applied to calculate the weighting coefficients. The weighting vector would be as follows:

$$
\mathbf{W}=\left[\begin{array}{llllll}
w_{1} & w_{2} & \ldots & w_{j} & \ldots & w_{m}
\end{array}\right]_{m \times 1}^{T}
$$

where $m$ is the number of criteria.

\subsection{Step 7: Determination of performance indices of materials and extracting the final ranking}

The performance index vector is obtained as shown in Eq. (4);

$$
\left[\begin{array}{ccccc}
r_{11} & \ldots & r_{1 j} & \ldots & r_{1 m} \\
\ldots & \ldots & \ldots & \ldots & \ldots \\
r_{i 1} & \ldots & r_{i j} & \ldots & r_{i m} \\
\ldots & \ldots & \ldots & \ldots & \ldots \\
r_{n 1} & \ldots & r_{n j} & \ldots & r_{n m}
\end{array}\right]_{n \times m} \times\left[\begin{array}{c}
w_{1} \\
\ldots \\
w_{j} \\
\ldots \\
w_{m}
\end{array}\right]_{m \times 1}=\left[\begin{array}{c}
\gamma_{1} \\
\ldots \\
\gamma_{i} \\
\ldots \\
\gamma_{n}
\end{array}\right]_{n \times 1}
$$

Arrays of this matrix multiplication represent each candidate material's performance in fulfilling the goals of the application. Materials with higher performance indices are more favorable and stand in better ranks. Lastly, Fig. 4 displays the step-by-step comparison between MFLM and the Conventional Fuzzy Logic Method [32]. In contrast to the traditional fuzzy approach, MFLM necessitates neither an enormous number of IF-THEN rules nor fuzzification and defuzzification interfaces. 


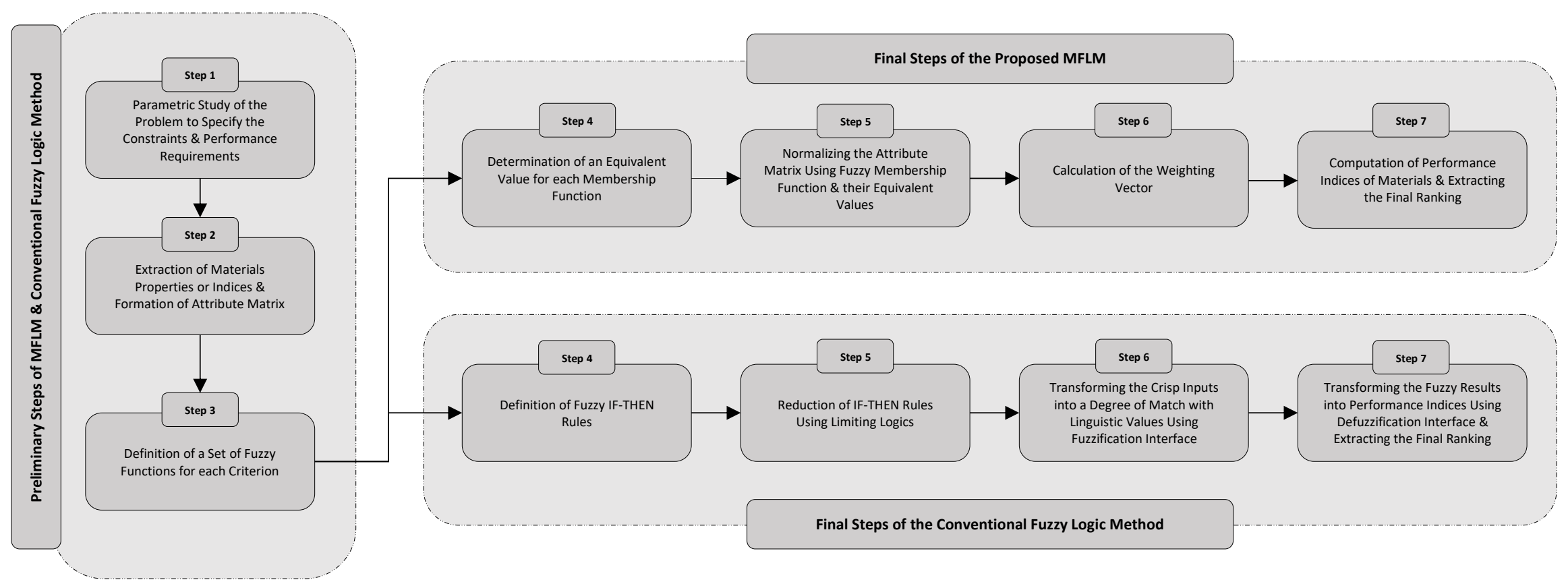

Fig. 4 Step-by-step comparison between MFLM and the Conventional Fuzzy Logic Method 


\section{Supplementary notes}

A Matlab code is developed to execute the method. This code performs all of the computational steps (i.e., steps 4 to 7 ) of the proposed technique. It receives a matrix of attributes [D], a matrix of fuzzy functions, a vector that specifies the number of functions for each criterion, and finally, a binary vector that separates cost and beneficial criteria as input data. Then, utilizing the defined functions calculates the performance indices and final ranking of materials. Since the offered ranking system is based on simple algebraic equations, there is no major computational hurdle that must be tackled.

Indeed, the only challenge of applying the presented technique is defining the characteristics of fuzzy membership functions, including their number, mapping interval, and location (i.e., step 3). These functions inform the system of how accurate our data is and how the data should be normalized by dividing the considered range of materials properties into some groups. In other words, sets of fuzzy membership functions capture the qualitative viewpoint of the designer and apply it to simplify the procedure of decision-making based on uncertainties. Some of the fuzzy-based approaches have tried to limit the functions to certain ones with fixed locations to reduce the difficulties of function mapping $[\underline{31}, \underline{42}]$. However, by doing so, functions lose their flexibility to represent unclear data. MFLM offers designers the chance to map their tailored fuzzy membership functions and customize the selection scheme. Bear in mind that, in many other fuzzy-based ranking systems such as the Conventional Fuzzy Logic method [32], which formed the foundation of the current research, the nomination of functions is left to designers' hands. MFLM, similar to other existing approaches, guarantees reliable results unless the functions are not well-fitted to the data. Consequently, decision-makers are not advised to apply MFLM if either precise numerical data is available or satisfying function mapping is beyond reach. 


\section{Verification of the proposed method}

In this section, MFLM has been applied to three standard mechanical design cases, and the final rankings are compared with some reliable methods such as TOPSIS [7]], Z-transformation [10], and the conventional Fuzzy Logic [32].

\subsection{Cryogenic Storage tanks}

Liquid hydrogen, oxygen, nitrogen, and liquefied natural gas (LNG) are among the gases stored at cryogenic temperature for various applications such as fuel cell, power generation, etc. [43]. Consequently, candidate materials for a cryogenic storage tank should possess adequate specific strength, specific stiffness, and toughness at the operating temperature. Satisfying weldability and processability, and good heat insulation are among other necessities. The requirements mentioned above lead the decision-maker to choose the proper cost and beneficial criteria for the materials selection procedure.

\subsubsection{Step 1 \& 2:}

Density, specific heat, thermal expansion coefficient, and thermal conductivity are among the cost properties, and toughness, stiffness, and strength are the beneficial properties considered as criteria. Candidate materials and their corresponding properties are listed in Table 1.

Table 1 Properties of candidate materials for a cryogenic storage tank

\begin{tabular}{|c|c|c|c|c|c|c|c|}
\hline Materials & Toughness index ${ }^{\mathrm{a}}$ & $\begin{array}{l}\text { Yield strength } \\
\text { (Mpa) }\end{array}$ & $\begin{array}{l}\text { Young's modulus } \\
\text { (Gpa) }\end{array}$ & Density $\left(\mathrm{g} / \mathrm{m}^{3}\right)$ & Thermal expansion $^{\mathrm{b}}$ & Thermal conductivity $^{\mathrm{c}}$ & Specific heat ${ }^{\mathrm{d}}$ \\
\hline $\mathrm{Al} 2024-\mathrm{T} 6$ & 75.5 & 420 & 74.2 & 2.80 & 21.4 & 0.370 & 0.16 \\
\hline Al 5052-O & 95 & 91 & 70 & 2.68 & 22.1 & 0.330 & 0.16 \\
\hline SS 301-FH & 770 & 1365 & 189 & 7.90 & 16.9 & 0.040 & 0.08 \\
\hline SS $310-3 \mathrm{AH}$ & 187 & 1120 & 210 & 7.90 & 14.4 & 0.030 & 0.08 \\
\hline Ti-6Al-4V & 179 & 875 & 112 & 4.43 & 9.4 & 0.016 & 0.09 \\
\hline Inconel-718 & 239 & 1190 & 217 & 8.51 & 11.5 & 0.310 & 0.07 \\
\hline $70 \mathrm{Cu}-30 \mathrm{Zn}$ & 273 & 200 & 112 & 8.53 & 19.9 & 0.290 & 0.06 \\
\hline
\end{tabular}




\subsubsection{Step 3 \& 4:}

In this step, a set of triangular fuzzy membership functions for each attribute is defined. Also, the equivalent values of the functions are calculated by applying Eqs. (1), (2). These values are shown in Table 2.
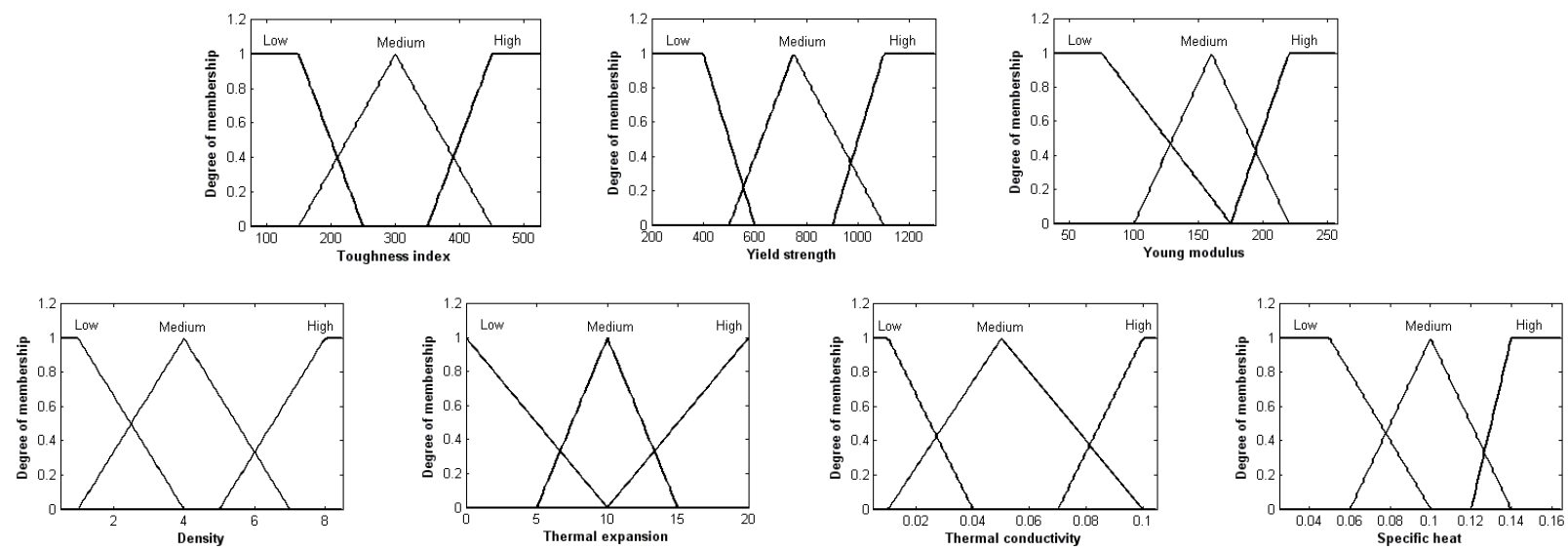

Fig. 5 Defined fuzzy membership functions for a cryogenic storage tank

Table 2 Equivalent values of fuzzy membership functions for a cryogenic storage tank

\begin{tabular}{|c|c|c|c|c|c|c|c|}
\hline Membership functions & Toughness Index & Yield strength & Young's modulus & Density & Thermal expansion & Thermal conductivity & Specific heat \\
\hline Low & 0.125 & 0.111 & 0.204 & 0.857 & 0.833 & 0.875 & 0.821 \\
\hline Medium & 0.5 & 0.518 & 0.561 & 0.571 & 0.5 & 0.525 & 0.462 \\
\hline High & 0.875 & 0.889 & 0.882 & 0.143 & 0.167 & 0.125 & 0.091 \\
\hline
\end{tabular}

\subsubsection{Step $5 \& 6$ \& 7:}

The crisp data of candidate materials (Table 1) are converted into normalized values using Eq. (3). The obtained normalized matrix is listed in Table 3. The weighting vector is also calculated based on MDL [6] method, and the values are as in Table 4. 
Table 3 Normalized values of the candidate materials for a cryogenic storage tank

\begin{tabular}{|c|c|c|c|c|c|c|c|}
\hline Materials & Toughness index & Yield strength & Young's modulus & Density & Thermal expansion & Thermal conductivity & Specific heat \\
\hline $\mathrm{Al} 2024-\mathrm{T} 6$ & 0.125 & 0.131 & 0.204 & 0.587 & 0.167 & 0.125 & 0.091 \\
\hline $\mathrm{Al} 5052-\mathrm{O}$ & 0.125 & 0.111 & 0.204 & 0.599 & 0.167 & 0.125 & 0.091 \\
\hline SS 301-FH & 0.875 & 0.889 & 0.673 & 0.143 & 0.218 & 0.569 & 0.611 \\
\hline SS $310-3 \mathrm{AH}$ & 0.217 & 0.889 & 0.839 & 0.143 & 0.273 & 0.656 & 0.611 \\
\hline Ti-6Al-4V & 0.192 & 0.584 & 0.287 & 0.376 & 0.521 & 0.834 & 0.518 \\
\hline Inconel-718 & 0.414 & 0.889 & 0.87 & 0.143 & 0.441 & 0.125 & 0.725 \\
\hline $70 \mathrm{Cu}-30 \mathrm{Zn}$ & 0.466 & 0.111 & 0.287 & 0.143 & 0.168 & 0.125 & 0.785 \\
\hline
\end{tabular}

Table 4 Application of modified digital logic method to the cryogenic storage tank

\begin{tabular}{|c|c|c|c|c|c|c|c|c|c|c|c|c|c|c|c|c|c|c|c|c|c|c|c|}
\hline \multirow{2}{*}{ Materials Properties } & \multicolumn{21}{|c|}{ Number of possible decisions } & \multirow{2}{*}{$\begin{array}{l}\text { Positive } \\
\text { decisions }\end{array}$} & \multirow{2}{*}{$\begin{array}{l}\text { Weighting } \\
\text { Coefficient }\end{array}$} \\
\hline & 1 & 2 & 3 & 4 & 5 & 6 & 7 & 8 & 9 & 10 & 11 & 12 & 13 & 14 & 15 & 16 & 17 & 18 & 19 & 20 & 21 & & \\
\hline Toughness index & 3 & 3 & 3 & 3 & 3 & 3 & & & & & & & & & & & & & & & & 18 & 0.214 \\
\hline Yield strength & 1 & & & & & & 3 & 1 & 2 & 3 & 3 & & & & & & & & & & & 13 & 0.155 \\
\hline Young modulus & & 1 & & & & & 1 & & & & & 1 & 1 & 3 & 3 & & & & & & & 10 & 0.119 \\
\hline Density & & & 1 & & & & & 3 & & & & 3 & & & & 3 & 3 & 3 & & & & 16 & 0.19 \\
\hline Thermal expansion & & & & 1 & & & & & 2 & & & & 3 & & & 1 & & & 3 & 3 & & 13 & 0.155 \\
\hline Thermal conductivity & & & & & 1 & & & & & 1 & & & & 1 & & & 1 & & 1 & & 2 & 7 & 0.083 \\
\hline Specific heat & & & & & & 1 & & & & & 1 & & & & 1 & & & 1 & & 1 & 2 & 7 & 0.083 \\
\hline
\end{tabular}

Finally, the performance indices for the candidate materials are obtained using Eq. (4). The final ranking of the candidate materials by the proposed method and other conventional ranking approaches are listed in Table 5.

Table 5 Performance indices and ranking of candidate materials for a cryogenic storage tank

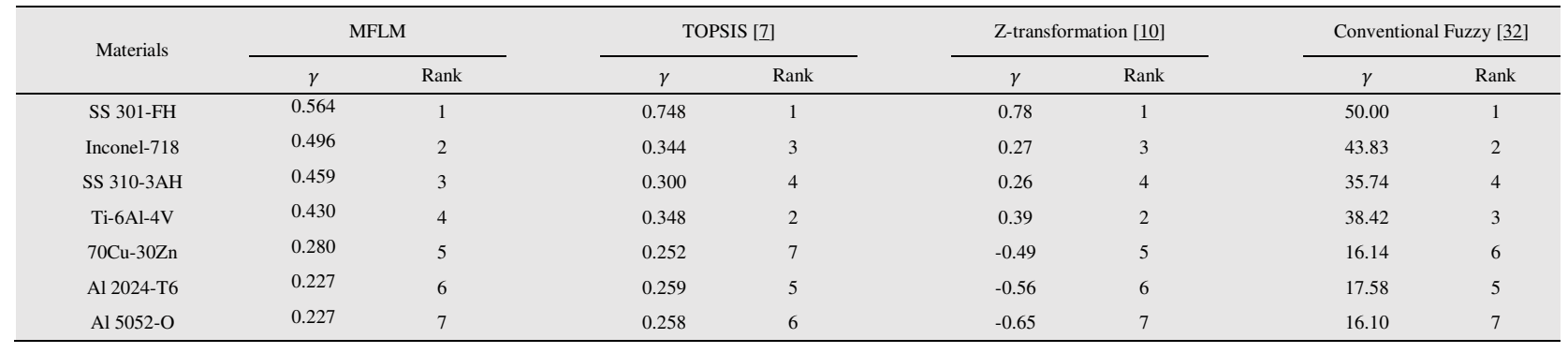

According to Table 5, TOPSIS and Z-transformation methods allocate the second rank to Ti-6Al4V; however, based on MFLM and Conventional Fuzzy ranking results, Inconel-718 stands in second place. Ti-6Al-4V demonstrates an extraordinarily low thermal conductivity compared to other candidate materials, and its density is less than Inconel-718. Nevertheless, its performance corresponding to all other beneficial criteria is weaker than Inconel-718 and even SS 310-3AH. TOPSIS and Z-transformation methods cannot identify a design scope 
corresponding to each criterion for the application; as a result, materials with only one or two exceptional property values would earn better rankings. It is also the case for the third and fourth ranks of the Conventional Fuzzy method. This major flaw is resolved in MFLM by mapping the membership functions in each criterion's favorable design interval. To elaborate on this, see the set of membership functions for the Thermal conductivity property in Fig. 5. Values of candidate materials corresponding to this property range from 0.016 to 0.370 ; however, the design span for this criterion in which membership functions are mapped is from 0 to 0.12 . It allows the decision-maker to balance the adverse influences of a material with an extraordinary property on the overall ranking results. Note that the final ranking would be much closer to the results of the mentioned methods if the set of fuzzy functions were defined in the total interval values of candidate materials.

\subsection{Gas turbine blades}

\subsubsection{Step 1 \& 2:}

Unlike the previous example, materials indices are considered as criteria to show the capability of the proposed method in solving problems under different circumstances. Materials indices that are obtained based on operating conditions and also fatigue requirements-are as follows:

$M_{1}=\left(\frac{\sigma_{y}}{\rho}\right)^{0.5}, M_{2}=\left(\frac{E}{\rho}\right), M_{3}=\sigma_{y}, M_{4}=\left(\frac{E}{\rho}\right)^{0.5}, M_{5}=\left(\frac{\sigma_{y}}{E \alpha}\right), M_{6}=\left(\frac{k}{\rho c}\right), M_{7}:$ Creep rupture stress, $M_{8}=\left(\right.$ elongation $\left.\times \frac{\left(\sigma_{y}+\sigma_{u t}\right)}{2}\right), M_{9}=T_{m}, M_{10}$ : Oxidation resistance, $M_{11}$ : Corrosion resistance, where $\sigma_{y}, \sigma_{u t}, \rho, E, \alpha, k, \mathrm{c}$, and $T_{m}$ are yield stress, ultimate tensile stress, density, Young's modulus, thermal expansion coefficient, thermal conductivity, specific heat, and melting temperature, respectively. Details of extracting these indices can be found in reference [14]. Since a turbine blade experiences a wide temperature range in its working environment, accurate properties of the candidate materials at different temperature points should be considered. Over the past two decades, the working temperature of gas turbines has risen from $1000-1300{ }^{\circ} \mathrm{F}$ to $1300-1800{ }^{\circ} \mathrm{F}$. Also, the non-operating temperature is assumed to be $70{ }^{\circ} \mathrm{F}$. 
Table 6 provides the selected material indices and their values for screened candidate materials, respectively. 
Table 6 Indices of candidate materials at different temperature points for a gas turbine blade

\begin{tabular}{|c|c|c|c|c|c|c|c|c|c|c|c|c|c|c|c|c|c|c|c|c|c|c|c|c|c|}
\hline Superalloys & $\stackrel{?}{\frac{i}{\Sigma}}$ & $\frac{\frac{8}{0}}{\frac{1}{\Sigma}}$ & $\frac{\stackrel{8}{ \pm}}{\frac{1}{\Sigma}}$ & $\frac{\frac{8}{d}}{\dot{\Sigma}}$ & $\frac{\frac{8}{0}}{\frac{1}{\Sigma}}$ & $\begin{array}{l}\frac{8}{\infty} \\
\frac{\infty}{\dot{J}} \\
\end{array}$ & $\begin{array}{l}\stackrel{0}{1} \\
\frac{i}{2}\end{array}$ & $\frac{8}{\frac{\delta}{\dot{d}}}$ & $\begin{array}{l}\stackrel{8}{\pi} \\
\frac{1}{\tilde{I}}\end{array}$ & $\frac{8}{\frac{8}{\dot{d}}}$ & $\begin{array}{l}\frac{8}{0} \\
\frac{1}{\check{I}}\end{array}$ & $\begin{array}{l}8 \\
\frac{\infty}{\dot{1}} \\
\stackrel{\tilde{\Sigma}}{\Sigma}\end{array}$ & 六 & $\frac{8}{\frac{8}{1}}$ & $\frac{8}{\stackrel{1}{1}}$ & 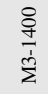 & $\begin{array}{l}8 \\
\frac{8}{0} \\
\frac{1}{2}\end{array}$ & 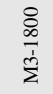 & 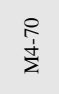 & $\frac{8}{\frac{8}{d}}$ & $\frac{\stackrel{d}{\pi}}{\frac{1}{+}}$ & $\frac{\stackrel{8}{+}}{\frac{1}{\dot{f}}}$ & $\frac{8}{0}$ & 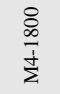 & $\frac{8}{\frac{8}{1}} \frac{1}{n}$ \\
\hline Hastelloy S & 15.02 & 12.84 & 12.71 & 12.17 & 11.31 & 7.34 & 103.7 & 88.89 & 84.85 & 81.14 & 76.09 & 70.71 & 67 & 49 & 48 & 44 & 38 & 16 & 10.18 & 9.428 & 9.211 & 9.008 & 8.723 & 8.409 & 0.221 \\
\hline Hastelloy X & 3.19 & 11.53 & 10.52 & 10.37 & 9.413 & 6.414 & 94.3 & 81.65 & 78.16 & 73.73 & 70.25 & 64.56 & 55 & 42 & 35 & 34 & 28 & 13 & 9.711 & 9.036 & 8.841 & 8.587 & 8.382 & 8.035 & 0.22 \\
\hline Haynes HR-120 & 12.52 & 9.398 & 9.25 & 9.343 & 9.632 & 8.165 & 98.28 & 81.1 & 77.32 & 73.2 & 68.73 & 64.6 & 45.6 & 25.7 & 24.9 & 25.4 & 27 & 19.4 & 9.914 & 9.006 & 8.793 & 8.555 & 8.29 & 8.038 & 0.121 \\
\hline Haynes HR-160 & 12.5 & 9.345 & 9.382 & 9.197 & 8.7 & 6.082 & 104.8 & 87.67 & 83.56 & 78.42 & 74.32 & 67.81 & 45.6 & 25.5 & 25.7 & 24.7 & 22.1 & 10.8 & 10.24 & 9.363 & 9.141 & 8.856 & 8.621 & 8.235 & 0.12 \\
\hline Haynes 230 & 13.72 & 11.65 & 11.6 & 12.03 & 10.23 & 7.495 & 94.44 & 81.48 & 78.09 & 74.38 & 71.3 & 67.59 & 61 & 44 & 43.6 & 46.9 & 33.9 & 18.2 & 9.718 & 9.027 & 8.837 & 8.625 & 8.444 & 8.221 & 0.219 \\
\hline Haynes 282 & 18.65 & 17.73 & 17.64 & 17.45 & 15.73 & 7.972 & 105.4 & 90.97 & 86.96 & 82.61 & 76.59 & 68.9 & 104 & 94 & 93 & 91 & 74 & 19 & 10.26 & 9.538 & 9.325 & 9.089 & 8.751 & 8.3 & 0.461 \\
\hline Haynes 625 & 15.26 & 13.43 & 13.31 & 12.8 & 9.918 & 6.273 & 99.02 & 83.93 & 79.67 & 74.75 & 69.51 & 61.31 & 71 & 55 & 54 & 50 & 30 & 12 & 9.951 & 9.162 & 8.926 & 8.646 & 8.337 & 7.83 & 0.265 \\
\hline Inconel 600 & 12.65 & 11.72 & 11 & 9.218 & 7.231 & 5.113 & 101.6 & 87.25 & 83.33 & 79.41 & 74.51 & 68.63 & 49 & 42 & 37 & 26 & 16 & 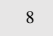 & 10.08 & 9.341 & 9.129 & 8.911 & 8.632 & 8.284 & 0.187 \\
\hline Inconel 601 & 10.93 & 9.05 & 9.599 & 9.776 & 7.838 & 6.127 & 102.4 & 86.69 & 82.25 & 76.79 & 69.97 & 62.8 & 35 & 24 & 27 & 28 & 18 & 11 & 10.12 & 9.311 & 9.069 & 8.763 & 8.365 & 7.925 & 0.111 \\
\hline Inconel 625 & 15.58 & 14.03 & 14.26 & 14.03 & 11.59 & 8.098 & 98.69 & 84.92 & 80.98 & 76.39 & 70.16 & 63.93 & 74 & 60 & 62 & 60 & 41 & 20 & 9.934 & 9.215 & 8.999 & 8.74 & 8.376 & 7.996 & 0.297 \\
\hline Inconel 718 & 24.07 & 22.73 & 22.32 & 20.18 & 12.58 & 8.308 & 97.64 & 83.5 & 79.8 & 75.08 & 68.01 & 58.59 & 172 & 153.5 & 148 & 121 & 47 & 20.5 & 9.881 & 9.138 & 8.933 & 8.665 & 8.247 & 7.654 & 0.764 \\
\hline Haynes 556 & 14.33 & 10.86 & 10.7 & 10.54 & 9.881 & 7.34 & 100 & 77.78 & 73.4 & 73.4 & 70.37 & 67.68 & 61 & 35 & 34 & 33 & 29 & 16 & 10 & 8.819 & 8.567 & 8.567 & 8.389 & 8.227 & 0.172 \\
\hline Incoloy 8 & 11.2 & 11.04 & 10.56 & 8.755 & 6.858 & 4.939 & 98.95 & 81.53 & 77.7 & 73.52 & 69.69 & 65.51 & 36 & 35 & 32 & 22 & 13.5 & 7 & 9.948 & 9.03 & 8.815 & 8.574 & 8.348 & 8.094 & 0.159 \\
\hline Incoloy $800 \mathrm{H}$ & 11.04 & 7.919 & 7.696 & 7.919 & 7.696 & 6.73 & 98.95 & 81.53 & 77.7 & 73.52 & 69.69 & 65.51 & 35 & 18 & 17 & 18 & 17 & 13 & 9.948 & 9.03 & 8.815 & 8.574 & 8.348 & 8.094 & 0.082 \\
\hline Incoloy $800 \mathrm{HT}$ & 11.04 & 7.919 & 7.696 & 7.919 & 7.696 & 6.73 & 98.95 & 81.53 & 77.7 & 73.52 & 69.69 & 65.51 & 35 & 18 & 17 & 18 & 17 & 13 & 9.948 & 9.03 & 8.815 & 8.574 & .348 & 094 & 0.082 \\
\hline Haynes 1 & 41 & 11.39 & 11.07 & 10.96 & 10.5 & 7.658 & 85.19 & 80.86 & 76.85 & 72.84 & 68.83 & 64.81 & 67.3 & 42 & 39.7 & 38.9 & 35.9 & 19 & 9.23 & 8.992 & 8.767 & 535 & 296 & 051 & 0.208 \\
\hline Haynes 25 (L-605) & 14.46 & 10.44 & 12.06 & 11.15 & 10.44 & 7.385 & 98.48 & 78.18 & 73.64 & 69.09 & 64.85 & 60.3 & 69 & 36 & 48 & 41 & 36 & 18 & 9.924 & 8.842 & 8.581 & 8.312 & 8.053 & 766 & 0.174 \\
\hline MAR-M-247 & 19.98 & 20.86 & 20.94 & 21.01 & 20.23 & 18.02 & 64.94 & 56.17 & 53.25 & 50.32 & 47.4 & 44.81 & 123 & 134 & 135 & 136 & 126 & 100 & 8.058 & 7.495 & 7.297 & 7.094 & 6.885 & 6.694 & 0.922 \\
\hline CMSX-4 & 20.7 & 21.33 & 21.8 & 21.18 & 19.88 & 17.48 & 119.6 & 116.3 & 113.3 & 109.6 & 106.3 & 102.3 & 129 & 137 & 143 & 135 & 119 & 92 & 10.94 & 10.78 & 10.64 & 10.47 & 10.31 & 10.12 & 0.483 \\
\hline
\end{tabular}

\begin{tabular}{|c|c|c|c|c|c|c|c|c|c|c|c|c|c|c|c|c|c|c|c|c|c|c|c|c|c|}
\hline Superalloys & $\begin{array}{l}8 \\
\frac{1}{1} \\
\frac{1}{2}\end{array}$ & $\frac{8}{\frac{8}{\dot{b}}}$ & $\begin{array}{l}8 \\
\frac{0}{1} \\
\dot{n}\end{array}$ & $\begin{array}{l}8 \\
\frac{8}{\infty} \\
\dot{n} \\
\dot{n}\end{array}$ & $\begin{array}{l}\stackrel{0}{\circ} \\
\frac{\hat{b}}{2}\end{array}$ & $\begin{array}{l}\frac{8}{0} \\
\frac{0}{\dot{0}}\end{array}$ & $\begin{array}{l}\stackrel{8}{0} \\
\frac{\pi}{\delta}\end{array}$ & $\frac{8}{\frac{8}{1}}$ & $\begin{array}{l}8 \\
\frac{\delta}{0} \\
\frac{\dot{b}}{2}\end{array}$ & $\begin{array}{l}8 \\
\frac{\infty}{0} \\
\dot{b} \\
\frac{1}{2}\end{array}$ & $\begin{array}{l}8 \\
\frac{1}{1} \\
\frac{1}{\Sigma}\end{array}$ & $\frac{8}{\frac{8}{1}}$ & $\begin{array}{l}8 \\
\frac{n}{1} \\
\frac{n}{\Sigma}\end{array}$ & $\frac{8}{\frac{8}{1}}$ & $\frac{8}{\frac{8}{1}}$ & $\sum_{\Sigma}^{\infty}$ & $\begin{array}{l}\stackrel{2}{1} \\
\text { ̀े }\end{array}$ & $\frac{8}{\frac{8}{1}}$ & $\begin{array}{l}\stackrel{8}{1} \\
\frac{\pi}{\dot{2}}\end{array}$ & $\frac{8}{\frac{8}{7}}$ & $\begin{array}{l}8 \\
\frac{0}{1} \\
\frac{1}{2}\end{array}$ & $\frac{8}{\frac{8}{\infty}}$ & $\frac{8}{\frac{8}{1}} \frac{d}{\frac{1}{\Sigma}}$ & 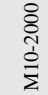 & $\overline{\bar{\Sigma}}$ \\
\hline Hastelloy S & 0.221 & 0.207 & 0.187 & 0.083 & 2587 & 4011 & 4261 & 4339 & 4274 & 4521 & 58 & 24.5 & 16 & 11.8 & 5.2 & 2300 & 4728 & 4025 & 4208 & 4580 & 2088 & 1054 & 0.5 & 1.3 & 29.5 \\
\hline Hastelloy X & 0.186 & 0.182 & 0.152 & 0.074 & 1719 & 3311 & 3438 & 3479 & 3449 & 3352 & 48 & 22.5 & 14.3 & 10.6 & 3.7 & 2435 & 3652 & 3060 & 3186 & 2677 & 2117 & 1268 & 0.9 & 2.7 & 29.5 \\
\hline Haynes HR-120 & 0.12 & 0.126 & 0.139 & 0.104 & 2393 & 3411 & 3580 & 3798 & 3890 & 4002 & 47 & 21.6 & 14.9 & 10.3 & 4.4 & 2375 & 3790 & 3224 & 2937 & 2235 & 1913 & 1920 & 3.7 & 7.7 & 0.9 \\
\hline Haynes HR-160 & 0.122 & 0.121 & 0.111 & 0.057 & 2335 & 3626 & 3674 & 3834 & 3863 & 4019 & 34 & 13 & 9.9 & 6.8 & 3.5 & 2360 & 5331 & 4077 & 3553 & 3168 & 2567 & 1404 & 5.9 & 10.3 & 1.1 \\
\hline Haynes 230 & 0.213 & 0.234 & 0.171 & 0.093 & 2014 & 3665 & 3409 & 3616 & 3810 & 4094 & 56 & 27 & 19 & 13.7 & 6 & 2375 & 4392 & 3942 & 4013 & 3809 & 2948 & 1080 & 0.7 & 1.3 & 12.6 \\
\hline Haynes 282 & 0.459 & 0.455 & 0.371 & 0.099 & 2315 & 3640 & 3918 & 3946 & 3958 & 4134 & 85 & 57 & 38 & 23 & 6.2 & 2370 & 4050 & 4046 & 3798 & 2365 & 2418 & 1562 & 1.8 & 10.9 & 2.2 \\
\hline Haynes 625 & 0.265 & 0.252 & 0.154 & 0.067 & 3186 & 3924 & 4028 & 4206 & 4401 & 4616 & 77 & 29 & 16.2 & 8.6 & 2.7 & 2350 & 4949 & 5163 & 4592 & 3631 & 2160 & 792 & 0.7 & 4.8 & 13.7 \\
\hline Inconel 600 & 0.169 & 0.12 & 0.077 & 0.041 & 2382 & 3245 & 3401 & 3479 & 3591 & 3674 & 23 & 8.4 & 6.3 & 4.8 & 2.8 & 2470 & 3020 & 2313 & 2639 & 2025 & 1197 & 650 & 0.9 & 1.6 & 12.5 \\
\hline Inconel 601 & 0.126 & 0.135 & 0.092 & 0.061 & 3208 & 3882 & 4011 & 4100 & 4209 & 4283 & 33 & 10.6 & 7.3 & 4.9 & 2.3 & 2375 & 3535 & 2725 & 2401 & 2720 & 1767 & 1260 & 1.3 & 2.6 & 2.9 \\
\hline Inconel 625 & 0.306 & 0.303 & 0.218 & 0.114 & 2911 & 3536 & 3655 & 3786 & 3906 & 4016 & 77 & 29 & 16.2 & 8.6 & 2.7 & 2350 & 5350 & 4656 & 3111 & 3150 & 5125 & 3020 & 0.72 & 4.8 & 1.7 \\
\hline Inconel 718 & 0.743 & 0.617 & 0.25 & 0.12 & 2636 & 3173 & 3298 & 3367 & 3430 & 3488 & 76.1 & 26.4 & 14.2 & 6.9 & 1.7 & 2300 & 3610 & 2877 & 2928 & 2846 & 2990 & 3465 & 0.5 & 1 & 0.2 \\
\hline Haynes 556 & 0.173 & 0.165 & 0.148 & 0.084 & 2427 & 3833 & 4051 & 4315 & 4449 & 4512 & 53 & 25 & 17 & 11.5 & 4.8 & 2425 & 4230 & 3456 & 3146 & 2575 & 2014 & 1408 & 1.1 & 2.6 & 3.8 \\
\hline Incoloy 800 & 0.149 & 0.105 & 0.066 & 0.035 & 2534 & 3510 & 3653 & 3830 & 4017 & 4575 & 24 & 9.5 & 6 & 4.4 & 1.9 & 2475 & 2684 & 2071 & 2139 & 2044 & 1344 & 810 & 1.4 & 8.2 & 0.4 \\
\hline Incoloy $800 \mathrm{H}$ & 0.079 & 0.086 & 0.083 & 0.066 & 2534 & 3510 & 3653 & 3830 & 4017 & 4575 & 22.5 & 9.4 & 6.1 & 3.9 & 1.7 & 2475 & 3207 & 2160 & 1731 & 1088 & 1755 & 1296 & 1.8 & 7.4 & 11 \\
\hline Incoloy $800 \mathrm{HT}$ & 0.079 & 0.086 & 0.083 & 0.066 & 2534 & 3510 & 3653 & 3830 & 4017 & 4575 & 22.5 & 9.4 & 6.1 & 3.9 & 1.7 & 2475 & 3207 & 2160 & 1731 & 1088 & 1755 & 1296 & 1.7 & 7.1 & 16 \\
\hline Haynes 188 & 0.194 & 0.194 & 0.183 & 0.099 & 2291 & 3491 & 3694 & 3935 & 3949 & 4167 & 72 & 37 & 17.5 & 11.6 & 4.3 & 2240 & 5419 & 4590 & 4219 & 4057 & 3069 & 1599 & 0.6 & 1.3 & 3.3 \\
\hline Haynes 25 (L-605) & 0.241 & 0.209 & 0.185 & 0.096 & 2141 & 3497 & 3726 & 3968 & 4242 & 4523 & 69 & 36 & 24.7 & 17.5 & 7.2 & 2425 & 5483 & 4484 & 4680 & 2814 & 2160 & 936 & 0.7 & 10.2 & 1.8 \\
\hline MAR-M-247 & 0.823 & 0.713 & 0.591 & 0.429 & 1743 & 3571 & 3732 & 3816 & 3944 & 4058 & 127 & 90.6 & 72 & 53 & 28 & 2400 & 1676 & 1465 & 1446 & 1371 & 1420 & 1748 & 0.5 & 1.1 & 2.1 \\
\hline CMSX-4 & 0.477 & 0.46 & 0.387 & 0.293 & 2161 & 4972 & 5287 & 5478 & 5596 & 5157 & 145 & 130 & 113 & 82 & 42 & 2901 & 1587 & 1358 & 1444 & 1770 & 2080 & 2024 & 0.7 & 1.3 & 3 \\
\hline
\end{tabular}




\subsubsection{Step 3 \& 4:}

Here, five triangular fuzzy membership functions are mapped in the interval defined by the minimum and maximum values of each material index of candidate materials. Fig. 6 shows the membership functions for the strength index at $1600{ }^{\circ} \mathrm{F}$ (i.e., M3-1600). The remaining sets of membership functions are similar and not repeated here. In addition, the equivalent values are obtained according to Eqs. (1), (2). These values for M3-1600 ${ }^{\circ} \mathrm{F}$ membership functions are as follows: $U_{V L}=0.134, U_{L}=0.357, U_{M}=0.532, U_{H}=0.706, U_{V H}=0.897$. The rest of the values is calculated likewise.

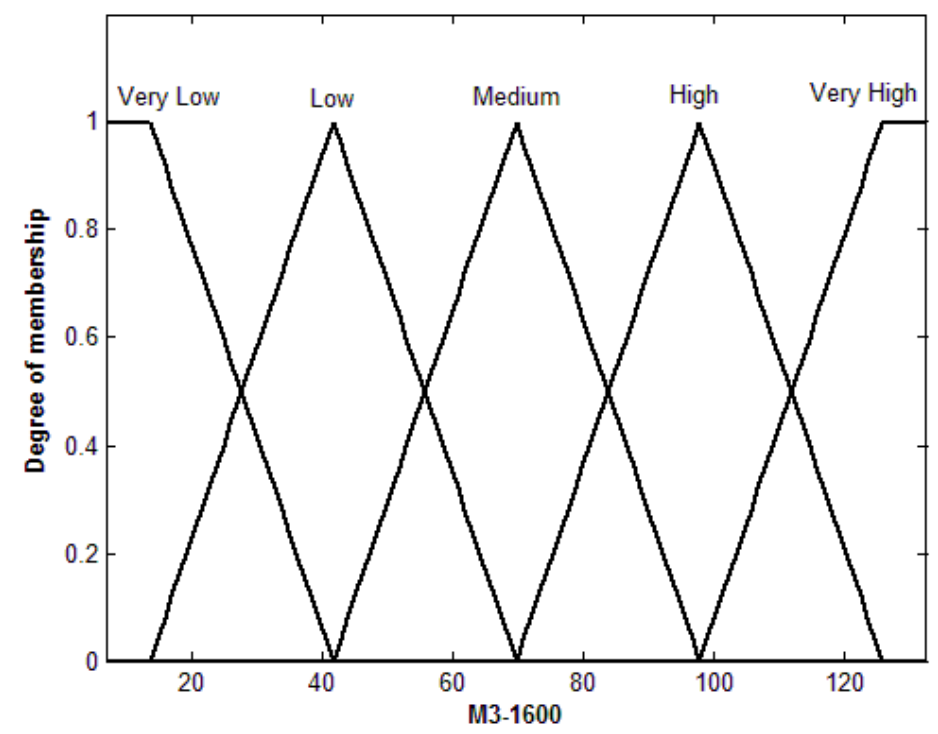

Fig. 6 Defined fuzzy membership functions of M3-1600 for a gas turbine blade

\subsubsection{Step 5:}

In this step, crisp numbers of Table 6, which gives the values of indices for candidate materials at different temperatures, are normalized by Eq. (3) and presented in Table 7. 
Table 7 Normalized indices of candidate materials at different temperature points for a gas turbine blade

\begin{tabular}{|c|c|c|c|c|c|c|c|c|c|c|c|c|c|c|c|c|c|c|c|c|c|c|c|c|c|}
\hline Super & $\frac{?}{\dot{1}}$ & $\frac{\frac{8}{0}}{\frac{1}{\Sigma}}$ & 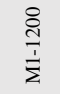 & $\frac{\stackrel{8}{\frac{8}{1}}}{\dot{\Sigma}}$ & $\frac{8}{\frac{8}{1}}$ & $\begin{array}{l}\stackrel{8}{\infty} \\
\frac{\infty}{\dot{\Sigma}}\end{array}$ & 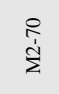 & $\frac{8}{\frac{8}{1}} \frac{1}{\tilde{d}}$ & $\begin{array}{l}\stackrel{d}{1} \\
\frac{1}{\Sigma}\end{array}$ & $\frac{\&}{\frac{8}{\dot{d}}}$ & $\begin{array}{l}\frac{8}{0} \\
\frac{1}{\tilde{d}} \\
\end{array}$ & $\begin{array}{l}8 \\
\frac{\infty}{\dot{1}} \\
\overline{\tilde{\Sigma}}\end{array}$ & $\begin{array}{l}\stackrel{1}{2} \\
\stackrel{\omega}{\Sigma}\end{array}$ & $\begin{array}{l}\frac{8}{0} \\
\frac{1}{\tilde{m}}\end{array}$ & $\begin{array}{l}\stackrel{8}{\pi} \\
\frac{\pi}{\grave{n}}\end{array}$ & $\frac{8}{\frac{8}{q}}$ & $\begin{array}{l}\frac{8}{0} \\
\frac{1}{2} \\
\sum\end{array}$ & $\begin{array}{l}8 \\
\frac{\infty}{1} \\
\dot{\omega} \\
\Sigma\end{array}$ & 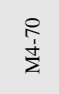 & $\frac{8}{\frac{8}{\dot{1}}}$ & 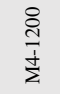 & $\frac{8}{\frac{8}{d}}$ & $\begin{array}{l}\frac{8}{0} \\
\frac{1}{+} \\
\frac{1}{2}\end{array}$ & $\frac{8}{\frac{8}{1}}$ & $\frac{8}{\frac{8}{1}}$ \\
\hline Hastelloy $S$ & 0.333 & 0.349 & 0.359 & 0.339 & 0.35 & 0.264 & 0.68 & 0.522 & 0.512 & 0.509 & 0.495 & 0.475 & 0.293 & 0.291 & 0.294 & 0.287 & 0.285 & 0.163 & 0.695 & 0.554 & 0.54 & 0.536 & 0.517 & 0.5 & 0.249 \\
\hline Hastelloy X & & 0.297 & 0.271 & 265 & 0.269 & 82 & 0.518 & 0.456 & 0.448 & 427 & 0.419 & 0.36 & 0.229 & 0.259 & 0.218 & 0.216 & 0.206 & 0.135 & 542 & 0.486 & 0.482 & 0.47 & 0.466 & 0.424 & 0.248 \\
\hline Haynes HR-120 & & 0.166 & 0.174 & 175 & 0.28 & 0.299 & 0.579 & 0.448 & 0.434 & 416 & 0.381 & 0.36 & 0.145 & 0.129 & 0.132 & 0.133 & 0.192 & 0.213 & 0.62 & 0.481 & 0.473 & 0.463 & 0.444 & 0.425 & 0.123 \\
\hline Haynes HR-160 & 191 & 0.163 & 0.185 & .163 & 0.218 & 0.154 & 0.691 & 0.511 & 0.502 & 0.488 & 0.479 & 0.433 & 0.145 & 0.128 & 0.136 & 0.129 & 0.144 & 0.12 & 0.703 & 0.538 & 0.526 & 0.51 & 0.503 & 0.475 & 0.122 \\
\hline Haynes 230 & 0.282 & 0.301 & 0.307 & 332 & 0.301 & 72 & 0.519 & 0.454 & 0.447 & 0.439 & 0.439 & 0.429 & 0.26 & 0.27 & 0.277 & 0.298 & 0.262 & 0.193 & 0.54 & 0.484 & 0.481 & 0.477 & 0.478 & 0.473 & 0.247 \\
\hline nes & 0.554 & 0. & 0. & 0.686 & 0.647 & 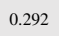 & 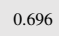 & 546 & 533 & 522 & 0.498 & 0.452 & 0. & 0.532 & 0.547 & 0.59 & 0.518 & 0.206 & 0.70 & 0.594 & 0.574 & 0.557 & 0.522 & .486 & 0.476 \\
\hline Haynes 625 & 347 & 0.395 & 0.413 & 0.39 & 0.291 & 0.169 & 0.598 & 0.482 & 0.468 & 0.446 & 0.4 & 0.317 & 0.31 & 0.31 & 0.315 & 0.309 & 0.23 & 0.127 & 0.64 & 0.503 & 0.494 & 0.481 & 0.456 & 0.349 & 0.285 \\
\hline In & 0. & 0.303 & 0.289 & 0.164 & 0.113 & 0.106 & 0.654 & 0.507 & 0.5 & 0.496 & 0.481 & 0.448 & 0.169 & 0.259 & 0.236 & 0.137 & 0.11 & 0.104 & & 0.533 & 0.523 & 0.518 & 0.504 & 0.484 & 0.201 \\
\hline nel 601 & 0. & 0.144 & 0.208 & 0.221 & 0.141 & 0.157 & 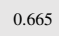 & 0.503 & 0.493 & 473 & 0.412 & 0.334 & 0.1 & 0.122 & 0.144 & 0.151 & 0.119 & 0.121 & 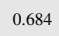 & 0.526 & 0.513 & 0.498 & 0.463 & 0.378 & 0.116 \\
\hline Inconel 625 & 0.371 & 0.446 & 0.474 & 0.481 & 0.372 & 0.296 & 0 . & 0.49 & 0.482 & 0.468 & 0.417 & 0.349 & 0.316 & 0.332 & 0.36 & 0.374 & 0.298 & 0.221 & 0.6 & 0.51 & 0.504 & 0.495 & 0.465 & 0.409 & 0.302 \\
\hline In & 0.9 & 0.9 & 0.9 & 857 & 0.46 & 0.303 & & 0.478 & 0.47 & 0.451 & 0.367 & 0.296 & 0.9 & 0.9 & 0.9 & 0.797 & 0.324 & 0.228 & 0.61 & 0.5 & 0.495 & 0.484 & 0.431 & 0.314 & 0.733 \\
\hline $\mathrm{H}_{\mathrm{H}}$ & 0.304 & 0.274 & 0.278 & 0.274 & 0.289 & 0.264 & 0.6 & 0.3 & 0.352 & 0.42 & 0.421 & 0.431 & 0.268 & 0.201 & 0.207 & 0.203 & 0.219 & 0.163 & 0.65 & 0.436 & 0.407 & 0.466 & 0.468 & .474 & 0.175 \\
\hline Incoloy 800 & (9y & 0.281 & 0.272 & 0.134 & 0.1 & 0.1 & 0.596 & 0.455 & 41 & 0.423 & 0.405 & 0.378 & 0.103 & 0.201 & 0.185 & 0.116 & 0.1 & 0.1 & 0.64 & 0.485 & 0.477 & 0.467 & 0.459 & .443 & 0.158 \\
\hline Incoloy & & 0.1 & 0.1 & 0.1 & & & & & & & & & 0.1 & 0.1 & 0.1 & 0.1 & 0.114 & 135 & & 0.485 & 0.477 & 0.467 & 0.459 & 443 & 0.1 \\
\hline Incoloy 800HT & 0.104 & 0.1 & 0.1 & 0.1 & 0.133 & 0.217 & 0.596 & 0.455 & 41 & 423 & 0.405 & 0.378 & 0.1 & 0.1 & 0.1 & 0.1 & 0.114 & 0.135 & 0.64 & 0.485 & 0.477 & 0.467 & 0.459 & .443 & 0.1 \\
\hline & & 0.293 & 0. & 0.291 & 0.311 & 0 & 0. & & 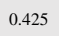 & 7 & 0.383 & 0.364 & 0. & 0.259 & 0.256 & 0.259 & .274 & 0.206 & 0.441 & 0.478 & 0.468 & 0.458 & 0.446 & .429 & 0.234 \\
\hline Haynes 25 (L-605 & 0.308 & 0.253 & & 0.297 & 0.308 & 0.266 & 0.583 & 0.387 & 0.356 & 0.336 & 0.323 & 0.308 & 0. & 0.212 & 0.294 & 0.272 & 0.275 & 0.19 & 0.631 & 0.443 & 0.413 & 0.38 & 0.357 & 0.334 & 0.179 \\
\hline MAR-M-247 & 0.668 & 0.797 & 0.839 & 0.895 & 0.9 & 0.9 & 0.1 & 0.1 & 0.1 & 0.1 & 0.1 & 0.1 & 0.624 & 0.774 & 0.834 & 0.9 & 0.9 & 0.9 & 0.1 & 0.1 & 0.1 & 0.1 & 0.1 & 0.1 & 0.9 \\
\hline CMSX-4 & 0.698 & 0.839 & 0.883 & 0.9 & 0.889 & 0.88 & 0.9 & 0.9 & 0.9 & 0.9 & 0.9 & 0.9 & 0.666 & 0.805 & 0.882 & 0.896 & 0.867 & 0.848 & 0.9 & 0.9 & 0.9 & 0.9 & 0.9 & 0.9 & 0.49 \\
\hline
\end{tabular}

\begin{tabular}{|c|c|c|c|c|c|c|c|c|c|c|c|c|c|c|c|c|c|c|c|c|c|c|c|c|c|}
\hline Superalloys & 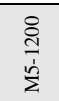 & $\begin{array}{l}8 \\
\frac{8}{1} \\
\frac{1}{2}\end{array}$ & $\begin{array}{l}8 \\
0 \\
\frac{1}{1} \\
2\end{array}$ & $\begin{array}{l}8 \\
\frac{8}{1} \\
\frac{n}{2}\end{array}$ & $\begin{array}{l}\stackrel{0}{\hat{j}} \\
\text { ऐo }\end{array}$ & $\begin{array}{l}\frac{8}{0} \\
\frac{0}{b}\end{array}$ & $\begin{array}{l}\text { \&े } \\
\frac{\mathrm{d}}{b} \\
\frac{b}{2}\end{array}$ & $\begin{array}{l}\frac{8}{q} \\
\frac{\dot{g}}{b}\end{array}$ & $\begin{array}{l}8 \\
\frac{8}{0} \\
\frac{b}{b}\end{array}$ & $\begin{array}{l}\frac{8}{\infty} \\
\frac{\infty}{b} \\
\frac{b}{\Sigma}\end{array}$ & $\begin{array}{l}\stackrel{8}{0} \\
\frac{1}{5}\end{array}$ & $\begin{array}{l}\frac{8}{9} \\
\frac{1}{\frac{1}{2}}\end{array}$ & $\begin{array}{l}\frac{8}{8} \\
\frac{1}{1} \\
\frac{1}{2}\end{array}$ & $\begin{array}{l}\frac{8}{0} \\
\frac{0}{1} \\
\frac{1}{\Sigma}\end{array}$ & $\begin{array}{l}8 \\
\frac{\infty}{1} \\
\frac{1}{\Sigma}\end{array}$ & $\sum_{z}^{\infty}$ & $\begin{array}{l}\stackrel{2}{2} \\
\text { হ̀̀े }\end{array}$ & $\begin{array}{l}8 \\
\frac{8}{1} \\
\frac{1}{2}\end{array}$ & 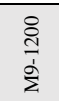 & $\begin{array}{l}\frac{8}{9} \\
\frac{8}{1} \\
\frac{1}{2}\end{array}$ & $\begin{array}{l}8 \\
\frac{8}{0} \\
\frac{0}{2}\end{array}$ & $\begin{array}{l}\frac{8}{\infty} \\
\frac{\infty}{1} \\
\frac{1}{2}\end{array}$ & $\begin{array}{l}8 \\
8 \\
01 \\
0 \\
\bar{\Sigma}\end{array}$ & 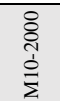 & $\bar{\Xi}$ \\
\hline Hastelloy S & 0.269 & 0.271 & 0.291 & 0.193 & 0.55 & 0.484 & 0.493 & 0.481 & 0.421 & 0.631 & 0.319 & 0.211 & 0.16 & 0.168 & 0.153 & 0.157 & 0.729 & 0.676 & 0.771 & 0.9 & 0.29 & 0.226 & 0.9 & 0.886 & 0.1 \\
\hline Hastelloy X & 0.226 & 0.237 & 0.247 & 0.165 & 0.1 & 0.144 & 0.139 & 0.127 & 0.104 & 0.1 & 0.28 & 0.187 & 0.145 & 0.152 & 0.125 & 0.322 & 0.514 & 0.473 & 0.518 & 0.478 & 0.293 & 0.286 & 0.858 & 0.746 & 0.1 \\
\hline Haynes HR-120 & 0.128 & 0.134 & 0.22 & 0.257 & 0.477 & 0.211 & 0.224 & 0.278 & 0.282 & 0.379 & 0.275 & 0.177 & 0.15 & 0.149 & 0.137 & 0.278 & 0.536 & 0.496 & 0.482 & 0.346 & 0.263 & 0.476 & 0.441 & 0.341 & 0.889 \\
\hline Haynes HR-160 & 0.13 & 0.129 & 0.151 & 0.129 & 0.447 & 0.301 & 0.268 & 0.287 & 0.275 & 0.392 & 0.16 & 0.118 & 0.117 & 0.117 & 0.122 & 0.262 & 0.882 & 0.684 & 0.635 & 0.562 & 0.365 & 0.308 & 0.1 & 0.132 & 0.886 \\
\hline Haynes 230 & 0.261 & 0.294 & 0.274 & 0.23 & 0.274 & 0.31 & 0.129 & 0.189 & 0.258 & 0.445 & 0.31 & 0.237 & 0.195 & 0.201 & 0.174 & 0.278 & 0.686 & 0.66 & 0.721 & 0.713 & 0.472 & 0.236 & 0.883 & 0.886 & 0.544 \\
\hline Haynes 282 & 0.504 & 0.554 & 0.548 & 0.246 & 0.434 & 0.304 & 0.333 & 0.311 & 0.298 & 0.464 & 0.504 & 0.433 & 0.324 & 0.298 & 0.181 & 0.273 & 0.611 & 0.679 & 0.69 & 0.386 & 0.332 & 0.342 & 0.704 & 0.1 & 0.862 \\
\hline Haynes 625 & 0.3 & 0.306 & 0.25 & 0.147 & 0.894 & 0.451 & 0.388 & 0.43 & 0.474 & 0.675 & 0.472 & 0.252 & 0.162 & 0.132 & 0.111 & 0.25 & 0.783 & 0.9 & 0.888 & 0.69 & 0.298 & 0.125 & 0.883 & 0.587 & 0.519 \\
\hline Inconel 600 & 0.192 & 0.128 & 0.109 & 0.106 & 0.472 & 0.119 & 0.126 & 0.127 & 0.142 & 0.26 & 0.102 & 0.1 & 0.101 & 0.105 & 0.112 & 0.364 & 0.389 & 0.3 & 0.391 & 0.308 & 0.1 & 0.1 & 0.858 & 0.868 & 0.547 \\
\hline Inconel 601 & 0.133 & 0.146 & 0.125 & 0.135 & 0.9 & 0.426 & 0.377 & 0.364 & 0.378 & 0.507 & 0.152 & 0.108 & 0.105 & 0.105 & 0.106 & 0.278 & 0.5 & 0.378 & 0.322 & 0.485 & 0.228 & 0.285 & 0.769 & 0.755 & 0.842 \\
\hline Inconel 625 & 0.328 & 0.362 & 0.318 & 0.275 & 0.725 & 0.276 & 0.261 & 0.274 & 0.286 & 0.389 & 0.472 & 0.252 & 0.162 & 0.132 & 0.111 & 0.25 & 0.884 & 0.788 & 0.506 & 0.557 & 0.9 & 0.758 & 0.881 & 0.587 & 0.874 \\
\hline Inconel 718 & 0.825 & 0.762 & 0.367 & 0.284 & 0.587 & 0.1 & 0.1 & 0.1 & 0.1 & 0.143 & 0.467 & 0.231 & 0.144 & 0.118 & 0.1 & 0.157 & 0.508 & 0.433 & 0.48 & 0.501 & 0.479 & 0.9 & 0.9 & 0.9 & 0.9 \\
\hline Haynes 556 & 0.202 & 0.2 & 0.239 & 0.197 & 0.489 & 0.388 & 0.405 & 0.474 & 0.487 & 0.625 & 0.3 & 0.217 & 0.17 & 0.164 & 0.144 & 0.314 & 0.66 & 0.526 & 0.512 & 0.458 & 0.28 & 0.308 & 0.82 & 0.755 & 0.803 \\
\hline Incoloy 800 & 0.16 & 0.114 & 0.1 & 0.1 & 0.523 & 0.266 & 0.26 & 0.286 & 0.309 & 0.659 & 0.105 & 0.104 & 0.1 & 0.103 & 0.102 & 0.373 & 0.314 & 0.267 & 0.283 & 0.311 & 0.118 & 0.129 & 0.75 & 0.31 & 0.897 \\
\hline Incoloy $800 \mathrm{H}$ & 0.1 & 0.1 & 0.115 & 0.145 & 0.523 & 0.266 & 0.26 & 0.286 & 0.309 & 0.659 & 0.1 & 0.103 & 0.1 & 0.1 & 0.1 & 0.373 & 0.449 & 0.281 & 0.155 & 0.1 & 0.224 & 0.291 & 0.704 & 0.371 & 0.61 \\
\hline Incoloy $800 \mathrm{HT}$ & 0.1 & 0.1 & 0.115 & 0.145 & 0.523 & 0.266 & 0.26 & 0.286 & 0.309 & 0.659 & 0.1 & 0.103 & 0.1 & 0.1 & 0.1 & 0.373 & 0.449 & 0.281 & 0.155 & 0.1 & 0.224 & 0.291 & 0.713 & 0.413 & 0.481 \\
\hline Haynes 188 & 0.238 & 0.254 & 0.288 & 0.246 & 0.414 & 0.259 & 0.274 & 0.308 & 0.296 & 0.476 & 0.438 & 0.294 & 0.175 & 0.165 & 0.135 & 0.1 & 0.893 & 0.766 & 0.775 & 0.767 & 0.49 & 0.354 & 0.892 & 0.886 & 0.827 \\
\hline Haynes 25 (L-605) & 0.285 & 0.272 & 0.289 & 0.238 & 0.315 & 0.261 & 0.284 & 0.316 & 0.4 & 0.632 & 0.407 & 0.29 & 0.257 & 0.256 & 0.217 & 0.314 & 0.9 & 0.74 & 0.9 & 0.498 & 0.298 & 0.168 & 0.883 & 0.139 & 0.872 \\
\hline MAR-M-247 & 0.9 & 0.9 & 0.9 & 0.9 & 0.107 & 0.287 & 0.286 & 0.283 & 0.295 & 0.423 & 0.77 & 0.658 & 0.588 & 0.606 & 0.636 & 0.297 & 0.11 & 0.113 & 0.1 & 0.148 & 0.129 & 0.421 & 0.9 & 0.896 & 0.865 \\
\hline CMSX-4 & 0.516 & 0.562 & 0.581 & 0.638 & 0.323 & 0.9 & 0.9 & 0.9 & 0.9 & 0.9 & 0.9 & 0.9 & 0.9 & 0.9 & 0.9 & 0.9 & 0.1 & 0.1 & 0.1 & 0.272 & 0.289 & 0.495 & 0.883 & 0.886 & 0.838 \\
\hline
\end{tabular}




\subsubsection{Step 6:}

This step aims to provide the equivalent weighting coefficients for each one of the material index-temperature point pairs. First, weighting factors for material indices should be determined. This task can be done using MDL [], QFD [14], or other weighting methods. However, since equal weighting coefficients for the material indices are taken into account by TOPSIS and Z-transformation methods, for a more meaningful comparison of the results with outputs of the named techniques, equal values are considered for eleven material indices. It means that the weighting coefficient for each material index is assumed to be $1 / 11$. Second, the weighting factors for temperature points should be calculated. This step could be quickly done by the MDL method, see Table 8 . Now with having weighting coefficients of material indices $\left(\alpha_{m}\right)$ and also point to point temperature weighting factors $\left(\alpha_{T}\right)$, equivalent weighting numbers can be defined by the following equation:

$$
\alpha_{e q}=\alpha_{m} \times \alpha_{T}
$$

It can be inferred from Eq. (5) that the changes in the working environment, like temperature fluctuations, which may cause variation in material indices, dictates the equivalent weighting coefficients $\left(\alpha_{e q}\right)$ to consist of proper weighting factors for all the influential working parameters. Here, in order to demonstrate the importance of each material index-temperature point pair, Eq. (5) first enables the decision-maker to consider materials data in a wide range of working temperatures $\left(\alpha_{m}\right)$, and second, value the material indices at more important temperature points $\left(\alpha_{T}\right)$. Note that since the materials data are not available at all temperature points, the points with available information are employed for some indices. For example, for the corrosion resistance index (M10), material indices are not presented in a broad range of working temperatures. As a result, materials data at 1800 and $2000^{\circ} \mathrm{F}$ are considered for evaluation. The equivalent weighting coefficients for each material index-temperature point are listed in Table 9. 
Table 8 Weighting coefficients of temperature points for a gas turbine blade

\begin{tabular}{|c|c|c|c|c|c|c|c|c|c|c|c|c|c|c|c|c|c|}
\hline \multirow{2}{*}{ Temp. ${ }^{\circ} \mathrm{F}$} & \multicolumn{15}{|c|}{ Number of possible decisions } & \multirow[t]{2}{*}{ Positive decisions } & \multirow[t]{2}{*}{ Coefficient $\alpha_{T}$} \\
\hline & 1 & 2 & 3 & 4 & 5 & 6 & 7 & 8 & 9 & 10 & 11 & 12 & 13 & 14 & 15 & & \\
\hline 70 & 1 & 1 & 1 & 1 & 1 & & & & & & & & & & & 5 & 0.083 \\
\hline 1000 & 3 & & & & & 1 & 1 & 1 & 1 & & & & & & & 7 & 0.117 \\
\hline 1200 & & 3 & & & & 3 & & & & 1 & 1 & 1 & & & & 9 & 0.150 \\
\hline 1400 & & & 3 & & & & 3 & & & 3 & & & 1 & 1 & & 11 & 0.183 \\
\hline 1600 & & & & 3 & & & & 3 & & & 3 & & 3 & & 1 & 13 & 0.217 \\
\hline 1800 & & & & & 3 & & & & 3 & & & 3 & & 3 & 3 & 15 & 0.250 \\
\hline
\end{tabular}

Table 9 Equivalent weighting factors of the material indices for a gas turbine blade

\begin{tabular}{|c|c|c|c|c|c|c|c|c|c|}
\hline Material Index & Value & Material Index & Value & Material Index & Value & Material Index & Value & Material Index & Value \\
\hline M1-70 & 0.007545 & M2-1600 & 0.019727 & M4-1200 & 0.013636 & M6-1000 & 0.010636 & M8 & 0.090909 \\
\hline M1-1000 & 0.010636 & M2-1800 & 0.022727 & M4-1400 & 0.016636 & M6-1200 & 0.013636 & M9-70 & 0.007545 \\
\hline M1-1200 & 0.013636 & M3-70 & 0.007545 & M4-1600 & 0.019727 & M6-1400 & 0.016636 & M9-1000 & 0.010636 \\
\hline M1-1400 & 0.016636 & M3-1000 & 0.010636 & M4-1800 & 0.022727 & M6-1600 & 0.019727 & M9-1200 & 0.013636 \\
\hline M1-1600 & 0.019727 & M3-1200 & 0.013636 & M5-1000 & 0.009090 & M6-1800 & 0.022727 & M9-1400 & 0.016636 \\
\hline M1-1800 & 0.022727 & M3-1400 & 0.016636 & M5-1200 & 0.013636 & M7-1200 & 0.009090 & M9-1600 & 0.019727 \\
\hline M2-70 & 0.007545 & M3-1600 & 0.019727 & M5-1400 & 0.018181 & M7-1400 & 0.013636 & M9-1800 & 0.022727 \\
\hline M2-1000 & 0.010636 & M3-1800 & 0.022727 & M5-1600 & 0.022727 & M7-1500 & 0.018181 & M10-1800 & 0.045454 \\
\hline M2-1200 & 0.013636 & M4-70 & 0.007545 & M5-1800 & 0.027272 & M7-1600 & 0.022727 & M10-2000 & 0.045454 \\
\hline M2-1400 & 0.016636 & M4-1000 & 0.010636 & M6-70 & 0.007545 & M7-1800 & 0.027272 & M11 & 0.090909 \\
\hline
\end{tabular}

\subsubsection{Step 7:}

By multiplying the normalized matrixs $\left(R_{19 \times 50}\right)$ with the weighting vector $\left(W_{50 \times 1}\right)$, the performance index vector and final ranking of the candidate materials can be extracted. The number 19 represents the number of candidate materials, and 50 indicates the number of material index-temperature point pairs. Table 10 presents the final ranking of the proposed method and the results obtained by the Z-transformation, QFD, and TOPSIS methods. As it is seen, there is extensive compatibility between the results obtained by different methods, and it proves the claim made earlier in this research work on the accuracy of the Modified Fuzzy Logic Method. Also, some minor discrepancies can be seen in the results. According to the TOPSIS method, candidate materials are ranked based on their distances from ideal and non-ideal solutions [7], meaning that materials are ranked relative to each other. Data dependency can adversely affect the results, especially when the designer faces candidate materials with low or high exceptional properties. These materials extend the range of property values and do not allow the decision-maker to differentiate the materials with close property values correctly. It is 
the case for TOPSIS rankings of materials Hastelloy S (rank 18) and Haynes 625 (rank 15). Surprisingly, although material indices of Haynes 25 (L-605) are so close to Hastelloy S, TOPSIS allocates the seventh place to this candidate material. MFLM resolved this major flaw by using its unique normalizing technique. Here, the defined sets of membership functions and their corresponding equivalent values act as auxiliary tools for accurately assessing the properties of materials and extracting their performance indices. Additionally, the poor performance of Haynes 188 corresponding to some material indices like corrosion resistance forced the QFD method to disregard its other valuable capabilities. On the other hand, MFLM can notice the requirements and objectives of the application and appreciate all of the favorable characteristics of different alternatives.

This example illustrates the power of the method in solving complex and hard-to-process problems. The enormous number of criteria (i.e., 50) makes it extremely time-consuming for conventional fuzzy logic-based approaches to provide the final ranking. For example, having 50 criteria and a set of 5 fuzzy membership functions leads to $5^{50}$ IF-THEN rules (before reduction) in the Conventional Fuzzy Logic method [32], making it inefficient while facing such elaborate problems. However, the proposed method allows us to confront complicated problems, besides giving us the undeniable advantages of the fuzzy environment. 
Table 10 Performance indices and ranking of candidate materials for a gas turbine blade

\begin{tabular}{|c|c|c|c|c|c|c|c|c|}
\hline \multirow{2}{*}{ Materials } & \multicolumn{2}{|c|}{ MFLM } & \multicolumn{2}{|c|}{ TOPSIS []] } & \multicolumn{2}{|c|}{ Z-transformation [10] } & \multicolumn{2}{|c|}{ QFD method [14] } \\
\hline & $\gamma$ & Rank & $\gamma$ & Rank & $\gamma$ & Rank & $\gamma$ & Rank \\
\hline CMSX-4 & 0.794 & 1 & 0.833 & 1 & 2.0786 & 1 & 2.038503 & 1 \\
\hline MAR-M-247 & 0.546 & 2 & 0.792 & 2 & 0.4076 & 2 & 0.437551 & 2 \\
\hline Inconel 718 & 0.498 & 3 & 0.630 & 3 & 0.2856 & 4 & 0.268965 & 4 \\
\hline Haynes 282 & 0.473 & 4 & 0.582 & 6 & 0.290 & 3 & 0.401309 & 3 \\
\hline Inconel 625 & 0.459 & 5 & 0.598 & 4 & 0.1763 & 5 & 0.135930 & 5 \\
\hline Haynes 188 & 0.421 & 6 & 0.586 & 5 & -0.066 & 7 & $0.14546-$ & 11 \\
\hline Haynes 556 & 0.416 & 7 & 0.563 & 8 & -0.013 & 6 & $0.07022-$ & 7 \\
\hline Haynes 230 & 0.407 & 8 & 0.500 & 12 & -0.090 & 10 & $0.14345-$ & 10 \\
\hline Haynes 625 & 0.403 & 9 & 0.463 & 15 & -0.072 & 8 & $0.09228-$ & 8 \\
\hline Haynes 25 (L-605) & 0.401 & 10 & 0.571 & 7 & -0.092 & 11 & $0.06205-$ & 6 \\
\hline Hastelloy S & 0.388 & 11 & 0.353 & 18 & -0.080 & 9 & $0.12437-$ & 9 \\
\hline Inconel 601 & 0.377 & 12 & 0.547 & 9 & -0.178 & 12 & $0.23988-$ & 13 \\
\hline Haynes HR-120 & 0.355 & 13 & 0.526 & 11 & -0.315 & 15 & $0.25074-$ & 14 \\
\hline Incoloy 800 & 0.347 & 14 & 0.539 & 10 & -0.307 & 13 & $0.28666-$ & 15 \\
\hline Inconel 600 & 0.344 & 15 & 0.463 & 14 & -0.311 & 14 & $0.34051-$ & 16 \\
\hline Haynes HR-160 & 0.334 & 16 & 0.473 & 13 & -0.362 & 16 & $0.23915-$ & 12 \\
\hline Incoloy $800 \mathrm{H}$ & 0.320 & 17 & 0.438 & 16 & -0.418 & 17 & $0.38783-$ & 17 \\
\hline Hastelloy X & 0.314 & 18 & 0.324 & 19 & -0.473 & 19 & $0.45904-$ & 19 \\
\hline Incoloy $800 \mathrm{HT}$ & 0.311 & 19 & 0.382 & 17 & -0.461 & 18 & 0.42858 & 18 \\
\hline
\end{tabular}

\subsection{Thermal barrier coatings (TBCs)}

\subsubsection{Introduction to TBCs:}

Superalloys experience mechanical and chemical degradations at high temperatures. In such cases, knowledge of surface engineering must be used to protect the parts. Tribology suggests using proper coatings to assure materials properties remain stable. All coatings applied to turbine blades should preserve the surface from the destructive effects of high-temperature corrosion, erosion, and oxidation due to combustion products. High strength under static and dynamic stresses, chemical inertness, and proper adhesion to the substrate are among other essential characteristics. Fig. 7 shows the flowchart of selecting an optimum material as a coating for gas turbine blades. 


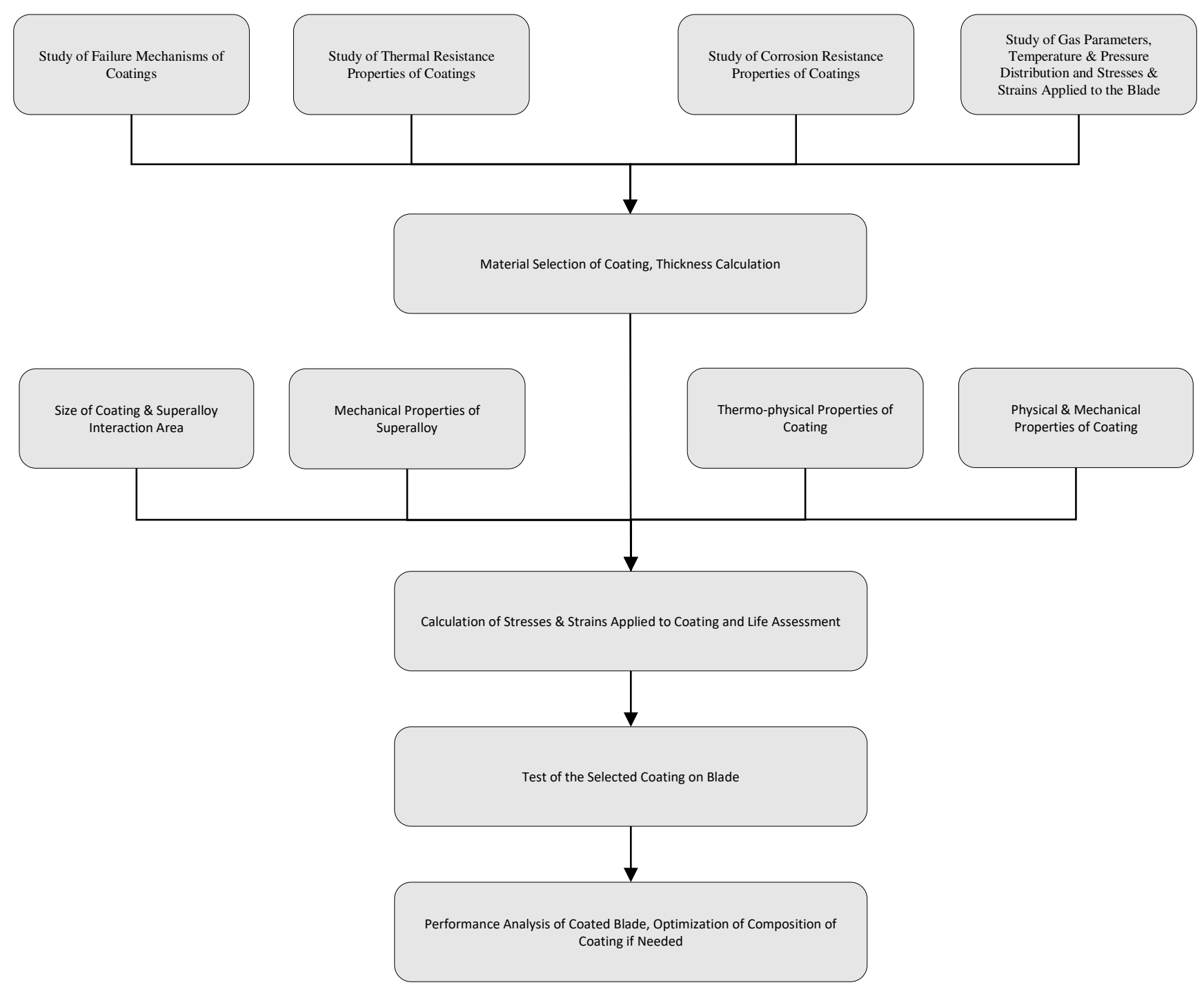

Fig. 7Flowchart of material selection for coatings of gas turbine blades

The application of thermal barrier coatings (TBCs) in turbine engines is quite common [44]. In this type of coatings, a ceramic layer is applied on the surface of the superalloy. Ceramics, due to their low thermal conductivity, provide thermal insulators that keep the temperature of sublayers much lower than the operating temperature of the engine. Perforated TBCs with $300 \mu \mathrm{m}$ thickness can cause temperature differences of up to hundreds of degrees of Celsius between the hot gas and the blade superalloy [ㅍ]. New TBC generations mostly made up of YSZ are used for turbine blades, nozzles, and some parts of the combustion chamber. 
Unfortunately, YSZ and many other coatings cannot prevent the penetration of oxygen, so the underlying layer is exposed to oxidation. In addition, the difference between thermal expansion coefficients of coatings and superalloys can lead to thermal stresses and eventually spallation of coatings. A layer called bond coating is applied to superalloy prior to the ceramic coating to reduce these adverse effects.

\subsubsection{Materials selection for TBCs}

Since the method description is fully clarified in the previous examples, the step-by-step explanation is skipped here. Thermal stresses caused by the difference in thermal expansion coefficients of the blade coating and superalloy substrate is calculated by Eq. (6) as follows;

$$
\sigma=\frac{E_{c}\left(\alpha_{T}-\alpha_{T c}\right)\left(T-T_{0}\right)}{1-v}
$$

where $E_{c}$ is the elastic modulus of coating, $\alpha_{T}$ and $\alpha_{T c}$ are thermal expansion coefficients of superalloy and coating, respectively, $v$ is the Poisson's ratio of coating, $\mathrm{T}$ is the operating temperature of the turbine, and $T_{0}$ is the initial temperature. This stress should not exceed the yield stress of coating $\left(\sigma_{y}\right)$. Hence, the first material index is obtained as;

$$
M_{1}=\frac{\sigma_{y}(1-v)}{E_{c}\left(\alpha_{T}-\alpha_{T c}\right)}
$$

The relatively large thickness of the applied ceramic coating can lead to high stresses due to

centrifugal loads. Therefore, its specific strength, which is defined as $M_{2}=\frac{\sigma_{y}}{\rho}$, is of great importance. Here, $\sigma_{y}$ and $\rho$ are the yield stress and density of the coating, respectively. The first two material indices are among the beneficial criteria. Also, smaller thermal conductivity and thermal expansion coefficient, higher melting point temperature, and good shock resistance are of interest. So, materials indices are defined as $M_{3}=k, M_{4}=\alpha, M_{5}=$ $T_{m}, M_{6}$ : shock resistance. Here, $k$ is the thermal conductivity, $\alpha$ is the thermal expansion 
coefficient, and $T_{m}$ is the melting temperature point. Moreover, as all ceramics exhibit good oxidation and corrosion resistance, these properties have been neglected. The final candidate materials and their indices are listed in Table 11.

Table 11 Indices of candidate materials for TBCs

\begin{tabular}{ccccccc}
\hline Materials & M1 & M2 & M3 & M4 & M5 & M6 \\
\hline ZrO2 & 8.76 & 2.74 & 1.62 & 0.7 & 2973 & High \\
3YSZ & 5.353 & 1.658 & 1.23 & 0.58 & 2719 & Very High \\
8YSZ & 7.933 & 1.898 & 0.83 & 0.21 & 2973 & Very High \\
Mullite & 3.152 & 3.571 & 1.39 & 0.14 & 2123 & Medium \\
Al2O3 & 35.09 & 2.71 & 5.8 & 0.47 & 2323 & Low \\
CeO2 & 11.37 & 1.37 & 2.77 & 0.86 & 2873 & Very High \\
La2Zr2O7 & 5.464 & 1.667 & 1.56 & 0.54 & 2573 & High \\
BaZrO3 & 4.728 & 1.818 & 3.42 & 1.25 & 2963 & High \\
TiO2 & 3.568 & 2.5 & 3.3 & 0.52 & 2098 & Low \\
LaPO4 & 8.831 & 2.016 & 1.8 & 0.42 & 2343 & High \\
60\% Mullite-40\% & 4.142 & 2.66 & 1.31 & 0.39 & 2463 & High \\
YSZ BC Alloy & & & & & & \\
\hline
\end{tabular}

Similar to the gas turbine blade example, a set of five fuzzy membership functions is considered in the domain limited by the Min-Max values of each material index of candidate materials. Fig. 8 demonstrates membership functions for the thermal stress index $\left(M_{1}\right)$.

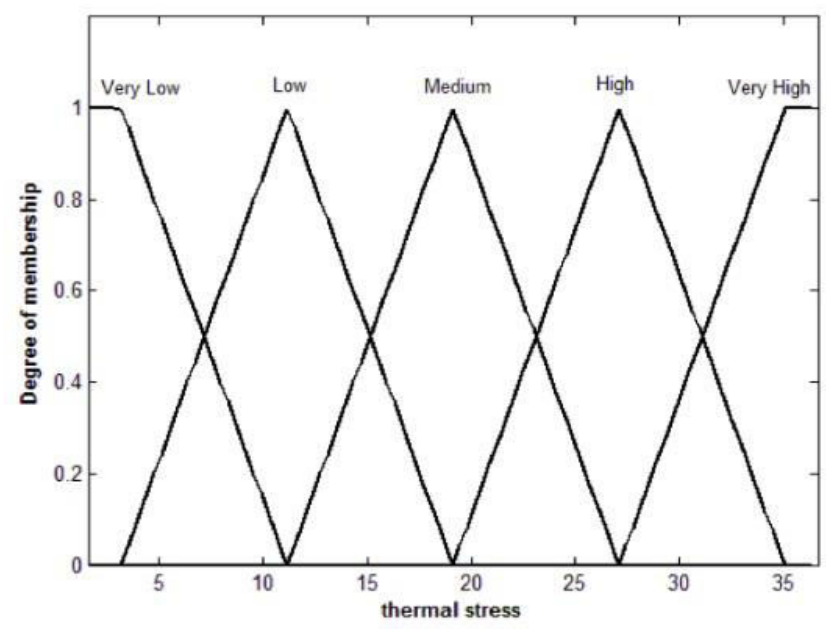

Fig. 8 Defined fuzzy membership functions for M1 material index

The equivalent values are calculated according to Eqs. (1) and (2), and subsequently, the crisp data presented in Table 11 are converted into normalized values (see Table 12). 
Table 12 Normalized indices of candidate materials for TBCs

\begin{tabular}{ccccccc}
\hline Materials & M1 & M2 & M3 & M4 & M5 & M6 \\
\hline ZrO2 & 0.258 & 0.596 & 0.757 & 0.498 & 0.9 & 0.7 \\
3YSZ & 0.138 & 0.209 & 0.853 & 0.571 & 0.681 & 0.9 \\
8YSZ & 0.233 & 0.296 & 0.9 & 0.866 & 0.9 & 0.9 \\
Mullite & 0.1 & 0.9 & 0.818 & 0.9 & 0.113 & 0.5 \\
Al2O3 & 0.9 & 0.577 & 0.1 & 0.677 & 0.303 & 0.3 \\
CeO2 & 0.303 & 0.1 & 0.578 & 0.368 & 0.816 & 0.9 \\
La2Zr2O7 & 0.141 & 0.215 & 0.77 & 0.621 & 0.521 & 0.7 \\
BaZrO3 & 0.125 & 0.277 & 0.491 & 0.1 & 0.895 & 0.7 \\
TiO2 & 0.105 & 0.506 & 0.501 & 0.641 & 0.1 & 0.3 \\
LaPO4 & 0.259 & 0.321 & 0.728 & 0.699 & 0.314 & 0.7 \\
60\% Mullite-40\% & 0.114 & 0.552 & 0.837 & 0.711 & 0.45 & 0.7 \\
YSZ BC Alloy & & & & & & \\
\hline
\end{tabular}

Furthermore, material indices are considered equally important, so the weighting coefficient for each one of them would be $1 / 6$. The final ranking results offered by MFLM, TOPSIS, and Ztransformation methods are summarized in Table 13. As was mentioned earlier, 8YSZ material stands in the first place by all ranking methods, except for the TOPSIS method, which allocates the first rank to $\mathrm{Al}_{2} \mathrm{O}_{3}$. The compatibility of thermal expansion coefficients of $\mathrm{Al}_{2} \mathrm{O}_{3}$ and superalloy substrate provides a higher thermal stress index $\left(M_{1}\right)$ for this coating. However, it does not justify the poor performance of $\mathrm{Al}_{2} \mathrm{O}_{3}$ in other indices compared to other candidates. Sacrificing other materials indices just because of one or two extraordinary characteristics is seen in the TOPSIS ranking. This flaw is prevented in the Modified Fuzzy Logic approach by mapping a suitable set of fuzzy membership functions in the design interval values of candidate materials.

Additionally, it can be inferred from Table 13 that the Z-transformation method does not notice the better shock resistance of 8 YSZ and 60\% Mullite-40\% YSZ BC Alloy over Mullite material; thus, Mullite earned third place by this ranking method. According to the scaling technique of the Z-transformation method, criteria with more dispersed values of candidate materials have less influence on the final ranking. This approach can cause severe problems, especially when facing qualitatively stated properties. Values attributed to the materials corresponding to these criteria are so scattered; as a result, the Z-transformation method always underestimates these attributes against quantitatively stated criteria. In contrast, MFLM uses equivalent values of membership functions combined with a weighting technique to fairly evaluate the materials. 
Table 13 Performance indices and ranking of candidate materials for TBCs

\begin{tabular}{|c|c|c|c|c|c|c|}
\hline \multirow{2}{*}{ Materials } & \multicolumn{2}{|c|}{ MFLM } & \multicolumn{2}{|c|}{ TOPSIS []] } & \multicolumn{2}{|c|}{ Z-transformation [10] } \\
\hline & $\gamma$ & Rank & $\gamma$ & Rank & $\gamma$ & Rank \\
\hline 8YSZ & 0.682 & 1 & 0.545 & 2 & 0.6506 & 1 \\
\hline $\mathrm{ZrO} 2$ & 0.618 & 2 & 0.472 & 6 & 0.3879 & 2 \\
\hline $\begin{array}{l}60 \% \text { Mullite }-40 \% \\
\text { YSZ BC Alloy }\end{array}$ & 0.561 & 3 & 0.479 & 5 & 0.2306 & 4 \\
\hline $3 \mathrm{YSZ}$ & 0.559 & 4 & 0.465 & 7 & 0.1595 & 5 \\
\hline Mullite & 0.555 & 5 & 0.5 & 3 & 0.2744 & 3 \\
\hline $\mathrm{CeO} 2$ & 0.511 & 6 & 0.416 & 9 & -0.059 & 8 \\
\hline $\mathrm{LaPO} 4$ & 0.504 & 7 & 0.488 & 4 & 0.0214 & 6 \\
\hline $\mathrm{La} 2 \mathrm{Zr} 2 \mathrm{O} 7$ & 0.495 & 8 & 0.446 & 8 & -0.059 & 7 \\
\hline $\mathrm{Al} 2 \mathrm{O} 3$ & 0.476 & 9 & 0.579 & 1 & -0.063 & 9 \\
\hline $\mathrm{BaZrO3}$ & 0.431 & 10 & 0.274 & 11 & -0.456 & 10 \\
\hline $\mathrm{TiO} 2$ & 0.359 & 11 & 0.353 & 10 & -0.58 & 11 \\
\hline
\end{tabular}

\section{Conclusion}

The vast range of alternatives, inadequate data, dual qualitative and quantitative nature of criteria, measurements inaccuracy, and occasionally conflicting attributes add up a great deal of uncertainty and vagueness to the selection scheme. In this sense, applying conventional weighted methods leaves the designer with imprecise and unreliable results. Generally, a fuzzy environment offers indisputable advantages to MCDM problems and aids the designer in deciding based on ambiguous and uncertain data. Nevertheless, the complexity and inaccuracy of conventional fuzzy logic approaches sometimes discourage one to practice these methods. MFLM endows the decision-maker with the opportunity to employ his/her knowledge and preferences by mapping a few simple fuzzy functions in the desired range and normalize the crisp data without struggling with any complicated IF-THEN rules or fuzzy operators. The significant advantages and highlights of the proposed fuzzy technique are summarized as follows;

1) MFLM exploits the newfound concept of the linear combination of equivalent values of surrounding membership functions as its novel normalizing technique. 
2) It passes the data through the filter of fuzzy membership functions to add the effects of uncertainties; thus, the produced rankings are more trustworthy than traditional numerical approaches.

3) MFLM is able to sense the presence of a specified design interval for each criterion and subsequently undermine the remarkable influences of out-of-box characteristics of materials on final rankings.

4) It can simultaneously incorporate both quantitative and qualitative criteria.

5) Depending on the application and availability of required knowledge, both materials properties and indices can be used as criteria.

6) This method does not require any complex IF-THEN rules or fuzzy operators.

7) The ranking results are independent of candidate materials.

8) The method is straightforward and can be programmed with a few lines of code.

9) Although this technique is particularly developed to facilitate the procedure of materials selection, it can be employed to other MCDM problems as well.

10) Remarkably, MFLM outperforms the existing complicated techniques in terms of accuracy, efficiency, and reliability. 


\section{Compliance with Ethical Standards}

Funding:

This research did not receive any specific grant from funding agencies in the public, commercial, or non-for-profit sectors.

Declaration of interests:

The authors declare that they have no known competing financial interests or personal relationships that could have appeared to influence the work reported in this paper.

Ethical approval:

This article does not contain any studies with human participants or animals performed by any of the authors.

Informed Consent:

The authors agree to submit the manuscript entiltled "Modified fuzzy logic method for materials selection in mechanical engineering design" to the journal of Soft Computing. 


\section{References}

[1] M. F. Ashby, "Materials selection in conceptual design," Mater. Sci. Technol., 1989.

[2] M. F. Ashby and D. Cebon, "Materials selection in mechanical design," J. Phys. IV Colloq., vol. 111, no. C7, p. 3, 1993, [Online]. Available: http://dx.doi.org/10.1051/jp4:1993701.

[3] A. M. Esawi and M. F. Ashby, "Systematic process selection in mechanical design," Int. Des. Eng. Tech. Conf. Comput. Inf. Eng. Conf., 1996.

[4] M. F. Ashby, "Multi-Objective Optimization in Material," Acta Mater., vol. 48, pp. 359369, 2000.

[5] M. M. Farag, “Materials selection for engineering design,” Prentice Hall, 1997.

[6] B. Dehghan-Manshadi, H. Mahmudi, A. Abedian, and R. Mahmudi, "A novel method for materials selection in mechanical design: Combination of non-linear normalization and a modified digital logic method," Mater. Des., vol. 28, no. 1, pp. 8-15, 2007, doi: 10.1016/j.matdes.2005.06.023.

[7] A. Shanian and O. Savadogo, "TOPSIS multiple-criteria decision support analysis for material selection of metallic bipolar plates for polymer electrolyte fuel cell," J. Power Sources, vol. 159, no. 2, pp. 1095-1104, 2006, doi: 10.1016/j.jpowsour.2005.12.092.

[8] F. Dweiri and P. M. Al-Oqla, "Material selection using analytical hierarchy process," Int. J. Comput. Appl. Technol., vol. 26, no. 4, pp. 182-189, 2006, doi: 10.1504/IJCAT.2006.010763.

[9] P. Chatterjee, V. M. Athawale, and S. Chakraborty, "Selection of materials using compromise ranking and outranking methods," Mater. Des., vol. 30, no. 10, pp. 40434053, 2009, doi: 10.1016/j.matdes.2009.05.016.

[10] K. Fayazbakhsh, A. Abedian, B. D. Manshadi, and R. S. Khabbaz, "Introducing a novel method for materials selection in mechanical design using Z-transformation in statistics 
for normalization of material properties," Mater. Des., vol. 30, no. 10, pp. 4396-4404, 2009, doi: 10.1016/j.matdes.2009.04.004.

[11] A. Jahan, M. Y. Ismail, F. Mustapha, and S. M. Sapuan, "Material selection based on ordinal data," Mater. Des., vol. 31, no. 7, pp. 3180-3187, 2010, doi: 10.1016/j.matdes.2010.02.024.

[12] K. Maniya and M. G. Bhatt, "A selection of material using a novel type decision-making method: Preference selection index method," Mater. Des., vol. 31, no. 4, pp. 1785-1789, 2010, doi: 10.1016/j.matdes.2009.11.020.

[13] R. V. Rao and B. K. Patel, "A subjective and objective integrated multiple attribute decision making method for material selection," Mater. Des., vol. 31, no. 10, pp. 47384747, 2010, doi: 10.1016/j.matdes.2010.05.014.

[14] A. Kasaei, A. Abedian, and A. S. Milani, "An application of quality function deployment method in engineering materials selection," Mater. Des., vol. 55, pp. 912-920, 2014, doi: 10.1016/j.matdes.2013.10.061.

[15] R. P. Cherian, L. N. Smith, and P. S. Midha, "Neural network approach for selection of powder metallurgy materials and process parameters," Artif. Intell. Eng., vol. 14, no. 1, pp. 39-44, 2000, doi: 10.1016/\$0954-1810(99)00026-6.

[16] E. I. Amoiralis, P. S. Georgilakis, and A. T. Gioulekas, "An artificial neural network for the selection of winding Material in power transformers," Lect. Notes Comput. Sci. (including Subser. Lect. Notes Artif. Intell. Lect. Notes Bioinformatics), vol. 3955 LNAI, pp. 465-468, 2006, doi: 10.1007/11752912_46.

[17] C. C. Zhou, G. F. Yin, and X. B. Hu, "Multi-objective optimization of material selection for sustainable products: Artificial neural networks and genetic algorithm approach," Mater. Des., vol. 30, no. 4, pp. 1209-1215, 2009, doi: 10.1016/j.matdes.2008.06.006.

[18] D. Golmohammadi, "Neural network application for fuzzy multi-criteria decision making problems," Int. J. Prod. Econ., vol. 131, no. 2, pp. 490-504, 2011, doi: 10.1016/j.ijpe.2011.01.015.

[19] P. J. Antony, P. Manujesh, and N. A. Jnanesh, "Data mining and machine learning approaches on engineering materials-A review," 2016 IEEE Int. Conf. Recent Trends 
Electron. Inf. Commun. Technol. RTEICT 2016 - Proc., pp. 69-73, 2017, doi: 10.1109/RTEICT.2016.7807785.

[20] X. Cui, S. Wang, and S. J. Hu, "A method for optimal design of automotive body assembly using multi-material construction," Mater. Des., vol. 29, no. 2, pp. 381-387, 2008, doi: 10.1016/j.matdes.2007.01.024.

[21] X. Cui, H. Zhang, S. Wang, L. Zhang, and J. Ko, "Design of lightweight multi-material automotive bodies using new material performance indices of thin-walled beams for the material selection with crashworthiness consideration," Mater. Des., vol. 32, no. 2, pp. 815-821, 2011, doi: 10.1016/j.matdes.2010.07.018.

[22] N. Sakundarini, Z. Taha, S. H. Abdul-Rashid, and R. A. R. Ghazila, "Optimal multi-material selection for lightweight design of automotive body assembly incorporating recyclability," Mater. Des., vol. 50, pp. 846-857, 2013, doi: 10.1016/j.matdes.2013.03.085.

[23] S. Kleemann, T. Fröhlich, E. Türck, and T. Vietor, "A Methodological Approach Towards Multi-material Design of Automotive Components," Procedia CIRP, vol. 60, pp. 68-73, 2017, doi: 10.1016/j.procir.2017.01.010.

[24] K. Anyfantis, P. Stavropoulos, P. Foteinopoulos, and G. Chryssolouris, "An approach for the design of multi-material mechanical components," Proc. Inst. Mech. Eng. Part B J. Eng. Manuf., vol. 233, no. 3, pp. 960-974, 2019, doi: 10.1177/0954405418763995.

[25] J. Zhang, Y. Huang, Y. Wang, and G. Ma, "Multi-objective optimization of concrete mixture proportions using machine learning and metaheuristic algorithms," Constr. Build. Mater., vol. 253, p. 119208, 2020, doi: 10.1016/j.conbuildmat.2020.119208.

[26] A. Sadollah and A. Bahreininejad, "Optimum gradient material for a functionally graded dental implant using metaheuristic algorithms," J. Mech. Behav. Biomed. Mater., vol. 4, no. 7, pp. 1384-1395, 2011, doi: 10.1016/j.jmbbm.2011.05.009.

[27] M. Jalal, A. K. Mukhopadhyay, and M. Goharzay, "Bat algorithm as a metaheuristic optimization approach in materials and design: optimal design of a new float for different materials," Neural Comput. Appl., vol. 31, no. 10, pp. 6151-6161, 2019, doi: 10.1007/s00521-018-3430-4. 
[28] T. Dokeroglu, E. Sevinc, T. Kucukyilmaz, and A. Cosar, "A survey on new generation metaheuristic algorithms," Comput. Ind. Eng., vol. 137, 2019, doi: 10.1016/j.cie.2019.106040.

[29] M. Abdel-Basset, L. Abdel-Fatah, and A. K. Sangaiah, Metaheuristic algorithms: A comprehensive review. Elsevier Inc., 2018.

[30] L. A. Zadeh, "Fuzzy logic," Comput. Complex. Theory, Tech. Appl., vol. 9781461418, pp. 1177-1200, 2013, doi: 10.1007/978-1-4614-1800-9_73.

[31] R. V. Rao, "A material selection model using graph theory and matrix approach," Mater. Sci. Eng. A, vol. 431, no. 1-2, pp. 248-255, 2006, doi: 10.1016/j.msea.2006.06.006.

[32] R. Sarfaraz Khabbaz, B. Dehghan Manshadi, A. Abedian, and R. Mahmudi, "A simplified fuzzy logic approach for materials selection in mechanical engineering design," Mater. Des., vol. 30, no. 3, pp. 687-697, 2009, doi: 10.1016/j.matdes.2008.05.026.

[33] J. Babu, A. James, J. Philip, and S. Chakraborty, "Application of the grey-based fuzzy logic approach for materials selection," Int. J. Mater. Res., vol. 108, no. 9, pp. 702-709, 2017, doi: 10.3139/146.111538.

[34] M. K. Rathod and H. V. Kanzaria, "A methodological concept for phase change material selection based on multiple criteria decision analysis with and without fuzzy environment," Mater. Des., vol. 32, no. 6, pp. 3578-3585, 2011, doi: 10.1016/j.matdes.2011.02.040.

[35] A. Mayyas, M. A. Omar, and M. T. Hayajneh, "Eco-material selection using fuzzy TOPSIS method," Int. J. Sustain. Eng., vol. 9, no. 5, pp. 292-304, 2016, doi: 10.1080/19397038.2016.1153168.

[36] A. S. Reddy, P. R. Kumar, and P. A. Raj, "Entropy-based fuzzy TOPSIS framework for selection of a sustainable building material," Int. J. Constr. Manag., vol. 0, no. 0, pp. 112, 2019, doi: 10.1080/15623599.2019.1683695.

[37] M. Gul, E. Celik, A. T. Gumus, and A. F. Guneri, "A fuzzy logic based PROMETHEE method for material selection problems," Beni-Suef Univ. J. Basic Appl. Sci., vol. 7, no. 1, pp. 6879, 2018, doi: 10.1016/j.bjbas.2017.07.002.

[38] O. Kulak and C. Kahraman, "Fuzzy multi-attribute selection among transportation 
companies using axiomatic design and analytic hierarchy process," Inf. Sci. (Ny)., vol. 170, no. 2-4, pp. 191-210, 2005, doi: 10.1016/j.ins.2004.02.021.

[39] K. Cicek and M. Celik, "Multiple attribute decision-making solution to material selection problem based on modified fuzzy axiomatic design-model selection interface algorithm," Mater. Des., vol. 31, no. 4, pp. 2129-2133, 2010, doi: 10.1016/j.matdes.2009.11.016.

[40] M. Celik, C. Kahraman, S. Cebi, and I. D. Er, "Fuzzy axiomatic design-based performance evaluation model for docking facilities in shipbuilding industry: The case of Turkish shipyards," Expert Syst. Appl., vol. 36, no. 1, pp. 599-615, 2009, doi: 10.1016/j.eswa.2007.09.055.

[41] A. V. Khandekar and S. Chakraborty, "Decision-making for materials selection using fuzzy axiomatic design principles," Int. J. Ind. Syst. Eng., vol. 20, no. 1, pp. 117-138, 2015, doi: 10.1504/IJISE.2015.069003.

[42] R. V. Rao, "A decision making methodology for material selection using an improved compromise ranking method," Mater. Des., vol. 29, no. 10, pp. 1949-1954, 2008, doi: 10.1016/j.matdes.2008.04.019.

[43] M. Seo and S. Jeong, "Analysis of self-pressurization phenomenon of cryogenic fluid storage tank with thermal diffusion model," Cryogenics (Guildf)., vol. 50, no. 9, pp. 549555, 2010, doi: 10.1016/j.cryogenics.2010.02.021.

[44] N. P. Padture, M. Gell, and E. H. Jordan, "Thermal barrier coatings for gas-turbine engine applications," Science (80-. )., vol. 296, no. 5566, pp. 280-284, 2002, doi: 10.1126/science.1068609.

[45] D. R. Clarke, "Materials Selection Guidelines for Low Thermal Conductivity Thermal Barrier Coatings Temperature Dependence of Thermal Conductivity Models for Thermal Conductivity," Surf. Coatings Technol., vol. 163-164, pp. 67-74, 2003. 